\title{
What Will Happen to Financial Markets When the Baby Boomers Retire?
}

\author{
Robin Brooks ${ }^{1}$
}

April 2000

\begin{abstract}
This paper explores the effects of demographic change on financial asset returns, using a calibrated overlapping generations model in which agents hold risky stocks and safe bonds. The model is solved numerically and yields portfolio behavior in which agents shift from stocks to bonds as they approach retirement. They behave in this manner because of human capital, a non-traded asset they implicitly hold over the life cycle. Using the model to simulate a baby boom and bust shows that at the turning point of the demographic shift when boom turns to bust - a large cohort of old boomers must trade with a smaller cohort of young investors. This demographic imbalance results in excess demand for the safe asset, which pushes the bond return down relative to the return on equity to clear the bond market. As a result the return on baby boomers' retirement savings is significantly below that of their parents, an effect baby boomers cannot diversify away. From a policy point of view this result is important because much of the debate over reform of public pension systems takes the historical distribution of asset returns - and the equity premium - as given.
\end{abstract}

JEL Classification Numbers: E27, G11, G12, H55

Keywords: equity premium, population aging, pension reform

\footnotetext{
${ }^{1}$ International Monetary Fund, Research Department, $70019^{\text {th }}$ Street, N.W., Washington, D.C., 20431; Tel: (202) 623-6236; Fax: (202) 623-6334. Email: rbrooks2@imf.org. Special thanks are due to Christopher Sims. I am also grateful to Luis Cubeddu, Wouter Den Haan, Hamid Faruqee, Peter Heller, Peter Isard, Ivailo Izvorski, Narayana Kocherlakota, Douglas Laxton, and Eswar Prasad for many helpful discussions and comments. Any errors are mine. Since this is a preliminary draft, please do not quote without permission.
} 


\section{Introduction}

This paper explores the effects of demographic change on financial asset returns. The aging of the baby boomers and speculation over possible effects on financial markets have raised the profile of this issue, both in the financial press and in academic circles. Broadly speaking, there are two opposing views. The first holds that retiring baby boomers will be selling their assets to a smaller generation of young investors. This will drive asset prices down, leaving baby boomers with a smaller nest-egg than anticipated. The second maintains that forward-looking financial markets are pricing assets to incorporate the aging of the boomer generation. As a result, there will not be a market meltdown when the baby boomers retire. This paper bridges the gap between these opposing arguments by asking the following question: can demographic change, which is slow-moving and predictable, have a significant impact on financial markets that are rational and forward-looking? It presents a model in which rational, forward-looking agents of different ages trade in financial assets and uses this framework to simulate a baby boom-baby bust of the kind observed in many developed countries over the post-war period. The main finding of the paper is that changes in the age distribution have significant effects on asset returns, even when investors are rational and forward-looking, and that these effects have important implications for the welfare of baby boomers and surrounding cohorts.

The model used is a stationary overlapping generations model with two assets: shares of ownership in risky capital and a riskless one-period bond in zero net supply. Agents live for four periods: childhood, young working-age, old working-age, and retirement. In childhood the agent relies on his parent for consumption and is not a decision maker. In both workingage periods he supplies labor inelastically and earns a wage. In retirement he consumes down his savings, there being no bequests. The model has two sources of aggregate uncertainty, a technology shock to production and random population growth, and is solved numerically using the parameterized expectations approach. Although agents' degree of risk aversion is constant over time, they invest as if increasingly risk averse with age: young workers short the riskless asset in order to hold equity, while old workers hold mostly the riskless asset. This portfolio behavior stems from the risk and life cycle characteristics of a nontradable asset, human capital, which agents implicitly hold. Young workers anticipate receiving wage income in old working-age, so that next period consumption does not depend on savings alone. In addition, since the return on capital is positively but imperfectly correlated with wage income, holding equity will diversify the effects of an adverse technology shock. In contrast, old workers' investment decision reflects the fact that next period consumption is out of savings alone. As a result they largely eliminate consumption risk by investing mostly in the riskless asset.

Using the model to simulate a baby boom-baby bust calibrated to match historical and projected population trends yields the following effects. First, there is an aggregate saving

${ }^{2}$ For examples of articles in the financial press, see Passell (1996) and Colvin (1997). 
effect on asset returns as changes in the age distribution affect aggregate saving and therefore the real interest rate. During the boom this effect will push up returns on capital and the riskless asset, a result of higher aggregate consumption because of relatively large cohorts of children. During the bust aggregate saving is relatively high, pushing returns on both assets down. Second, the return differential between stocks and bonds changes over the demographic shift. This effect derives from the fact that agents shift from stocks to bonds as they age. At the turning point of the boom-bust, when a large boomer cohort of old workers trades with a smaller cohort of young investors, this investment behavior generates excess demand for the riskless asset. As a result the bond return falls sharply relative to the return on capital and the return differential rises. Third, wage income moves inversely with the size of the labor force, even though capital accumulation in the model is endogenous.

These effects are significant. During the baby boom the expected one-period returns on stocks and bonds rise above their steady states by 4.8 and 9.4 percent respectively. On an annualized basis this means that the expected return on capital rises above its steady state of 4.54 percent by 14 basis points, while the riskfree rate is 28 basis points higher than its equilibrium level of 4.52 percent. During the baby bust the expected one-period return on capital falls below its steady state by up to 4.5 percent, while the riskfree rate falls by up to 12.1 percent below equilibrium. This translates respectively into up to 14 and 39 basis points on an annual basis. The greater sensitivity of the riskfree rate to the boom-bust is significant for older investors who want to minimize consumption risk in retirement. These magnitudes are also substantial relative to the impact of other fundamentals on asset returns. And while they are small relative to the recent run-up in stock prices, this simulation exercise holds nondemographic fundamentals constant over the boom-bust and ignores the possibility of a speculative bubble.

These effects go against baby boomers, especially those in the tail-end of the baby boom. But are baby boomers worse off? The simulated boom-bust consists of two boom followed by two bust periods, so that the first boomer cohort has relatively more children than the second. This pushes consumption per head of the first boomer cohort below equilibrium in parenthood. If utility of young workers is additively separable in their consumption and that of their children, this effect dominates adverse asset market effects. This means that lifetime utility of the first boomer cohort is below steady state, while that of the second is above because positive consumption effects in parenthood more than offset the effects of lower returns on retirement savings. In other words, adverse asset market effects are second-order. The fact that raising children is costly is more important. This result is reversed if young workers' utility is defined over household consumption. This specification reduces the effective weight in lifetime utility of consumption when young, so that adverse asset market effects dominate earlier positive consumption effects. Since the asset market implications of the model are qualitatively unchanged across specifications, and since it is not obvious how to model parents' utility, the reversal of the welfare result is interesting. It also points to a weakness of the model, since humans derive utility not only from consumption, but also from having children. As such, the welfare implications of the model should be taken with a grain of salt. 
The result that the return differential between stocks and bonds widens at the turning point of the boom-bust is arguably the most interesting result of the paper. As noted above it derives from two characteristics of the model: the shift from stocks to bonds over the life cycle, and the limited number of agents trading at any one point in time. A critic of this result might say: if baby boomers know they will retire in roughly 10 years, and that they may face adverse asset markets at that point, why not lock in wealth ahead of time? But this is exactly what boomer cohorts do in the model. In old working-age they invest in the riskless asset, in order to reduce consumption risk down the road. It is precisely this behavior, and the demographic imbalance, which drives down the bond relative to the stock return.

A number of papers have recently noted that a risk associated with switching to individual retirement accounts is that investors may be subject to adverse movements in asset prices that persist over time. 3 This paper makes this argument explicit, by presenting a framework in which investors are subject to cohort-specific risk that is linked to demographic change. Furthermore the model corresponds to a world in which pay-as-you-go pension systems have been replaced with individual retirement accounts, with no government regulation over agents' portfolio decisions. Thus the key result of the paper from a policy point of view is that the historical distribution of asset returns may be inappropriate for computing the gains to investors from switching to individual accounts, because the baby boomers are only now approaching retirement. Indeed the model suggests that baby boomers will earn returns that are substantially below returns to previous generations. ${ }^{4}$ This argument should not be understood as an endorsement of pay-as-you-go systems, since a defined-benefit pension system can be fully funded. Indeed, the paper augments the model with a simple pay-as-yougo pension scheme and shows that such a system does not eliminate cohort-specific demographic risk. Instead the paper underlines the role of government as an infinitely-lived agent, one that can insure agents against cohort-specific risk by adjusting government borrowing over time to stabilize the riskfree rate. Of course such a move would reflect a political consensus, since it involves transfers of wealth across generations.

There are a number of objections to the approach in this paper. It presents a closed economy model, which ignores investors' ability to insure against cohort-specific risk by holding an internationally diversified portfolio. Though this is an important consideration, most countries with significant asset markets have experienced post-war demographic shifts similar to the US. In effect, the model should be thought of as representing the developed world as a whole. Of course, there are regions with very different age distributions, such as

\footnotetext{
${ }^{3}$ See for example Heller (1998) and Hemming (1998).

${ }^{4}$ For papers that use the historical distribution of asset returns to compute gains from switching to individual retirement accounts see, for example, MaCurdy and Shoven (1992) and Feldstein and Ranguelova (1998).
} 
Africa or Latin America. However, it is unlikely that assets in these-markets have risk-return characteristics attractive to baby boomers preparing for retirement.

The model also ignores bequests. Bergantino (1998) finds that, using data from the Survey of Consumer Finances, intergenerational transfers are of minor importance to households. Fewer than 25 percent of households report having ever received a substantial inheritance, trust, or transfer. Of those that did, the median value in 1995 dollars was about $\$ 17,000$ per spouse, or about 60 percent of the median annual income. This evidence suggests that intergenerational transfers are of minor importance to most households, especially relative to wage income, in determining the life-cycle path of asset holdings.

A further shortcoming of the model is that it does not replicate the equity premium observed in the data. In large part this is because what is called equity in the model is not a levered asset, in the sense that there is no corporate debt. Adjusting for this the model supports a Sharpe ratio of roughly ten percent, the same order of magnitude as Storesletten, Telmer, and Yaron (1997) whose overlapping generations model has agent-specific, persistent income shocks. In contrast Constantinides, Donaldson, and Mehra (1998) generate an equity premium in an overlapping generations model in which young investors are borrowing constrained, which underscores that this model features no such market imperfection. The implicit assumption is that the behavior of relative returns over a demographic shift can be adequately characterized in the absence of such features.

The next section presents a brief overview of related papers. Section three presents the model, with subsequent sections devoted to equilibrium conditions and the solution method. Section eight discusses calibration of the model, while section nine characterizes the solution. Section ten uses the model solution to simulate the effects of a baby boom-baby bust on asset returns. Section 11 concludes.

\section{The Paper vis-à-vis the Literature}

The rationale for agents with constant risk aversion to substitute from equity to bonds as they age has been previously explored by Jaganathan and Kocherlakota (1996). They make the point that investors have fewer working years ahead of them as they age. Assuming that most

\footnotetext{
${ }^{5}$ Attanasio and Violante (2000) and Brooks (2000) explore the implications of historical and projected population trends for international capital flows. For a discussion of home country bias in portfolio allocation see French and Poterba (1991).

${ }^{6}$ For a review of recent papers on the equity premium see Kocherlakota (1996).

${ }^{7}$ A more recent discussion of the role of labor income as a non-traded asset and its impact on investment behavior over the life cycle can be found in Campbell, Cocco, Gomes, and Maenhout (1999).
} 
investors' labor incomes are poorly correlated with stock returns, they demonstrate that it is rational for agents to shift the composition of their financial wealth from stocks to less risky assets as they grow older. This paper demonstrates that this behavior obtains even when labor income and stock returns are positively correlated, a result of the interaction of the life cycle features of the model with the risk-return characteristics of the financial assets.

A number of empirical papers have recently explored the link between changes in the age distribution and financial markets. Bergantino (1998) presents evidence linking the level of real stock prices in the US to time series for aggregate demand of financial assets, which are derived from Survey of Consumer Finances data on portfolio composition by age. Brooks (1998) finds that real stock and bond prices across developed countries are positively related to the share of the population that is middle-aged, using the cross-section dimension of the data to control for unobserved fundamentals. In contrast Poterba (1998) fails to find a significant relationship between returns on a range of assets and different measures of the age distribution. Fundamentally, the problem that bedevils all empirical work is that the effective number of observations is small. As a result statistical tests have limited power. Perhaps this is the strongest argument for the simulation exercise that follows.

\section{The Model}

The representative agent lives for four periods: childhood, young working-age, old workingage, and retirement. In childhood the agent makes no decisions of his own, with consumption, $c_{t}{ }^{0}$, determined by the parent. In young working-age the agent inelastically supplies one unit of labor and earns a wage $w_{t}$. Out of wage income he consumes $c_{t}{ }^{l}$ for himself and assigns $\left(1+n_{t}\right) c_{t}{ }^{0}$ to his offspring where $n_{t}$ is the period $t$ cohort growth rate. In addition he may hold shares of ownership in risky capital, $s_{e t}{ }_{1}$, and invest $s_{b t}{ }_{1}$ in a riskless one-period bond in zero net supply. The budget constraint of a period $t$ young worker is thus:

$$
\left(1+n_{t}\right) c_{t}^{0}+c_{t}^{1}+s_{e t}^{1}+s_{b t}^{1}=w_{t}
$$

The agent reaches old working-age in period $t+1$. He again supplies one unit of labor inelastically, earning $w_{t+1}$, and receives income from stock and bond holdings chosen as a young worker. Out of total income he consumes only for himself since his children are now self-sufficient. He consumes $c_{t+1}{ }^{2}$, invests $s_{e t+1}^{2}$ in risky capital, and $s_{b t+1}{ }^{2}$ in the safe asset. The budget constraint of a period $t+1$ old worker is therefore:

$$
c_{t+1}^{2}+s_{e t+1}^{2}+s_{b t+1}^{2}=w_{t+1}+\left(1+r_{e t+1}\right) s_{e t}^{1}+\left(1+r_{f t}\right) s_{b t}^{1}
$$

\footnotetext{
${ }^{8}$ The approach in this paper contrasts with Bakshi and Chen (1994) who hypothesize that agents become more risk averse with age. They find that the average age of the US population is positively correlated with future excess returns on stocks over treasury bills.
} 
Here $r_{e t+1}$ is the return on equity held from period $t$ into period $t+1$, while $r_{f t}$ is the return on the riskless asset, held from period $t$ into period $t+1$. The agent reaches retirement in period $t+2$. He receives no wage income and consumes down his savings since there are no bequests. The budget constraint of a period $t+2$ retiree therefore amounts to a decision rule for consumption:

$$
c_{t+2}^{3}=\left(1+r_{e t+2}\right) s_{e t+1}^{1}+\left(1+r_{f t+1}\right) s_{b t+1}^{1}
$$

Preferences are described by an additively separable utility function. The expected lifetime utility of a period $t$ young worker is given by:

$$
V_{t}=\left(1+n_{t}\right) \frac{\left(c_{t}^{0}\right)^{1-\theta}}{1-\theta}+\frac{\left(c_{t}^{1}\right)^{1-\theta}}{1-\theta}+\beta E_{t}\left[\frac{\left(c_{t+1}^{2}\right)^{1-\theta}}{1-\theta}\right]+\beta^{2} E_{t}\left[\frac{\left(c_{t+2}^{3}\right)^{1-\theta}}{1-\theta}\right]
$$

The subjective discount factor is given by $\beta$ where $0<\beta<1$, while $\theta$ is the coefficient of constant relative risk aversion. The representative agent does not become more risk averse with age. This rather conventional specification of preferences is adopted to focus attention on the interaction of the life cycle dimension of the model with the representative agent's investment decision. The age distribution in period $t$ consist of $N_{t-1}$ young workers, $N_{t-2}$ old workers, and $N_{t-3}$ retirees. The period $t$ cohort of children is determined according to $N_{t}=\left(1+n_{t}\right) N_{t-1}$, where $n_{t}$ is the realization of a stationary cohort growth shock. Table 1 describes the evolution of the age distribution over time:

Table 1: The Age Distribution over Time

\begin{tabular}{ccccc}
\hline Period & Children & Young Workers & Old Workers & Retirees \\
\hline$t$ & $N_{t}$ & $N_{t-1}$ & $N_{t-2}$ & $N_{t-3}$ \\
$t+1$ & $N_{t+1}$ & $N_{t}$ & $N_{t-1}$ & $N_{t-2}$ \\
$t+2$ & $N_{t+2}$ & $N_{t+1}$ & $N_{t}$ & $N_{t-1}$ \\
$\Downarrow$ & $\Downarrow$ & $\Downarrow$ & $\Downarrow$ & $\Downarrow$ \\
\hline
\end{tabular}

Output is generated according to a constant returns to scale, neoclassical production function:

$$
Y_{t}=K_{t-1}^{\alpha}\left(A_{t} L_{t}\right)^{1-\alpha}
$$

where $\alpha$ determines the share of output rewarded to capital. $K_{t-1}$ is generated in period $t-1$ by the investment decisions of young and old workers. $A_{t}$ is the realization of a stationary laboraugmenting technology shock. $L_{t}$ consists of young and old workers so that $L_{t}=N_{t-1}+N_{t-2}$. Factor markets are efficient so that capital and labor are rewarded their marginal products.

$$
r_{e t}=\alpha K_{t-1}^{\alpha-1}\left(A_{t} L_{t}\right)^{1-\alpha}-\delta
$$




$$
w_{t}=(1-\alpha) K_{t-1}^{\alpha} A_{t}^{1-\alpha} L_{t}^{-\alpha}
$$

where $\delta$ is the depreciation rate. In equilibrium the capital stock used in period $t+1$ production is determined by share holdings of young and old workers chosen in period $t$ :

$$
K_{t}=N_{t-1} s_{e t}^{1}+N_{t-2} s_{e t}^{2}
$$

The equilibrium condition that the riskless one-period bond is in zero net supply implies that bond holdings of young and old workers sum to zero. In other words either young workers borrow from their parents or they lend to them.

$$
0=N_{t-1} s_{b t}^{1}+N_{t-2} s_{b t}^{2}
$$

Imposing these equilibrium conditions and aggregating across the budget constraints of young and old workers and retirees in period $t$ yields the social resource constraint:

$$
C_{t}+K_{t}-(1-\delta) K_{t-1}=K_{t-1}^{\alpha}\left(A_{t} L_{t}\right)^{1-\alpha}
$$

Output in period $t$ is divided into aggregate consumption and gross investment.

\section{Equilibrium}

Maximizing expected utility period $t$ young workers choose $c_{t}{ }^{0}, c_{t}{ }^{1}, s_{e t}{ }^{1}$, and $s_{b t}{ }^{1}$ such that

$$
\begin{aligned}
& c_{t}^{0}=c_{t}^{1} \\
& \left(c_{t}^{1}\right)^{-\theta}=\beta E_{t}\left[\left(c_{t+1}^{2}\right)^{-\theta}\left(1+r_{e t+1}\right)\right\rfloor
\end{aligned}
$$

\footnotetext{
${ }^{9}$ The model has two sources of aggregate uncertainty: the technology shock to production and the population growth rate. An investor deciding on how much equity to hold going forward into period $t+1$ does not know the realization of the period $t+1$ technology shock that determines $r_{e t+1}$. In contrast the return on the riskless asset in period $t+1$ is know in period $t$. Hence it is denoted $r_{f t}$, to emphasize that it is in agents' period $t$ information set. Similarly though $K_{t}$ enters production in period $t+1$, it is determined by investment decisions made in period $t$ and is therefore also in agents' period $t$ information set. The stochastic population growth rate represents aggregate uncertainty over cohort size. An unexpectedly large cohort of children has repercussions for agents' consumption-investment decision, as they react to a larger consumption requirement in young working-age and the larger labor force in subsequent periods.
} 


$$
\begin{aligned}
& \left(c_{t}^{1}\right)^{-\theta}=\beta\left(1+r_{f t}\right) E_{t}\left\lfloor\left(c_{t+1}^{2}\right)^{-\theta}\right\rfloor \\
& \left(1+n_{t}\right) c_{t}^{0}+c_{t}^{1}+s_{e t}^{1}+s_{b t}^{1}=w_{t}
\end{aligned}
$$

are satisfied, taking factor returns and the return on the riskless asset as given. Period $t$ old workers choose $c_{t}^{2}, s_{e t}^{2}$, and $s_{b t}{ }^{2}$ such that

$$
\begin{aligned}
& \left(c_{t}^{2}\right)^{-\theta}=\beta E_{t}\left[\left(c_{t+1}^{3}\right)^{-\theta}\left(1+r_{e t+1}\right)\right\rfloor \\
& \left(c_{t}^{2}\right)^{-\theta}=\beta\left(1+r_{f t}\right) E_{t}\left\lfloor\left(c_{t+1}^{3}\right)^{-\theta}\right\rfloor \\
& c_{t}^{2}+s_{e t}^{2}+s_{b t}^{2}=w_{t}+\left(1+r_{e t}\right) s_{e t-1}^{1}+\left(1+r_{f t-1}\right) s_{b t-1}^{1}
\end{aligned}
$$

are satisfied, again taking factor returns and the return on the riskless asset as given. Consumption of the period $t$ retiree cohort is given by:

$$
c_{t}^{3}=\left(1+r_{e t}\right) s_{e t-1}^{2}+\left(1+r_{f t-1}\right) s_{b t-1}^{2}
$$

(11) through (18) represent a system of eight equations that characterize individual consumption $\left(c_{t}^{0}, c_{t}, c_{t}^{2}, c_{t}^{3}\right)$ and investment behavior $\left(s_{e t}^{1}, s_{b t}^{1}, s_{e t}^{2}, s_{b t}^{2}\right)$ for given wage and return distributions. In equilibrium, consumption and investment decision rules that maximize expected utility at the individual level must be consistent with conditions (8) and (9), which are the equilibrium conditions for the stock and bond markets.

\section{The State Variables}

The model has only two active decision makers at any $t$ : young and old workers. Both make their consumption-investment decision based on total wealth, which for young workers is simply wage income.

$$
w_{t}^{1}=w_{t}
$$

Total wealth of old workers consists of wage income, in addition to stock and bond holdings and returns.

$$
w_{t}^{2}=w_{t}+\left(1+r_{e t}\right) s_{e t-1}^{1}+\left(1+r_{f t-1}\right) s_{b t-1}^{1}
$$

$w_{t}{ }^{1}$ and $w_{t}{ }^{2}$ describe the distribution of wealth across the two decision making cohorts in period $t$ and represent endogenous state variables. In addition the age distribution with the exception of the retiree cohort (which will not live to see the next period) represents an 
exogenous state variable. Thus the set of period $t$ state variables that describes the model looking ahead to period $t+1$ is:

$$
\Theta_{t}=\left\lfloor w_{t}^{1}, w_{t}^{2}, N_{t}, N_{t-1}, N_{t-2}\right\rfloor
$$

\section{The Solution Method}

The model is solved using the parameterized expectations approach (PEA). This approach is described in detail in Den Haan and Marcet (1990) who solve a one-good stochastic growth model. More recently Izvorski (1997) uses the PEA to solve a model with hetergeneous agents and incomplete markets. The essence of the PEA is that the conditional expectations on the right-hand sides of (12), (13), (15), and (16) each represent functions $g: R_{+}{ }^{5} \rightarrow R_{+}$of the state variables in $\Theta_{\mathrm{t}}$. This insight is used to substitute each conditional expectation with a function $\Pi\left(\Theta_{t}, \psi\right)$, where $\Pi$ (the functional form) and $\psi$ (the vector of parameters) will be chosen to make $\Pi\left(\Theta_{t}, \psi\right)$ as close as possible to $g$. Using the PEA (12), (13), (15), and (16) can be rewritten as:

$$
\begin{aligned}
& \left(c_{t}^{1}\right)^{-\theta}=\beta \Psi\left(\Theta_{t}, \tau\right) \\
& \left(c_{t}^{1}\right)^{-\theta}\left(s_{e t}^{1}\right)^{2}=\beta\left(1+r_{f t}\right) \Omega\left(\Theta_{t}, \gamma\right) \\
& \left(c_{t}^{2}\right)^{-\theta}=\beta \Lambda\left(\Theta_{t}, \xi\right) \\
& \left(c_{t}^{2}\right)^{-\theta}\left(s_{e t}^{2}\right)^{2}=\beta\left(1+r_{f t}\right) \Gamma\left(\Theta_{t}, \omega\right)
\end{aligned}
$$

Given two sequences of length $T$ for the technology shock and the age distribution, assuming starting values for $w_{t}{ }^{1}$ and $w_{t}{ }^{2}$, and given values for $\tau, \gamma, \xi$, and $\omega$, it is possible to solve out the model for $T$ periods. The PEA begins with exactly this step. It draws two sequences of length $T$ for the technology shock and the age distribution (both sequences are drawn only once), and solves out the model for $T$ periods. The PEA then turns to fitting the conditional expectations in (12), (13), (15), and (16), finding the coefficients in the polynomial approximations that minimize the mean squared error befween the actual realization in $t+1$ and the expectation at $t$ of that realization based on $\Theta_{\mathrm{t}}$.

\footnotetext{
${ }^{10}$ The conditional expectations in (13) and (16) have not been parameterized in the traditional manner. Both equations have been multiplied by functions of the respective equity holdings. This modification is based on Izvorski (1997) and addresses an indeterminacy in the system of Euler equations and aggregate equilibrium conditions that arises in models that solve for equilibrium holdings of two or more assets.
} 
The particular version of the PEA implemented here proceeds to fit the conditional expectations in a step by step approach. For the conditional expectation in (12) a non-linear least squares estimation for $\tau$ is performed:

$$
\min _{\tau} \frac{1}{T-1} \sum_{t=1}^{T-1}\left[\left(c_{t+1}^{2}\right)^{-\theta}\left(1+r_{e t+1}\right)-\Psi\left(\Theta_{t}, \tau\right)\right]^{2}
$$

At the $n$ 'th iteration a new value $\tau_{n+1}$ is generated according to $\tau_{n+1}=\lambda \tau_{n}+(1-\lambda) \tau_{e}$ where $\tau_{e}$ is the estimate for $\tau$ from the non-linear least squares estimation. Given $\tau_{n+1}, \gamma_{n}, \xi_{n}$, and $\omega_{n}$, the system is solved out again for $T$ periods and the algorithm proceeds to fit the other conditional expectations in turn. This procedure is repeated until the algorithm reaches a fixed point in $\tau, \gamma, \xi$, and $\omega$.

\section{Accuracy of the Solution Method}

The basic intuition of the PEA is to approximate conditional expectations of period $t+1$ using the information set available to agents at $t$. For a successful approximation the PEA prediction error should therefore be orthogonal to agents' information set at $t$. This intuition lies behind an accuracy test developed by Den Haan and Marcet (1994). The accuracy test checks for orthogonality between the Euler equation residuals and a vector $v_{t}$ of variables in agents' period $t$ information set.

$$
\left[\begin{array}{c}
\left(c_{t+1}^{2}\right)^{-\theta}\left(1+r_{e t+1}\right)-\Psi\left(\Theta_{t}, \tau^{*}\right) \\
\left(c_{t+1}^{2}\right)^{-\theta}\left(s_{e t}^{1}\right)^{2}-\Omega\left(\Theta_{t}, \gamma^{*}\right) \\
\left(c_{t+1}^{3}\right)^{-\theta}\left(1+r_{e t+1}\right)-\Lambda\left(\Theta_{t}, \xi^{*}\right) \\
\left(c_{t+1}^{3}\right)^{-\theta}\left(s_{e t}^{2}\right)^{2}-\Gamma\left(\Theta_{t}, \omega^{*}\right)
\end{array}\right]=\varepsilon_{t+1}
$$

where $\tau^{*}, \gamma^{*}, \xi^{*}$, and $\omega^{*}$ are the PEA parameter estimates at convergence. For any $m \times 1$ vector $v_{t}$ in agents' period $t$ information set, the statistic

${ }^{11}$ The implementation of the PEA follows Den Haan and Marcet (1990). Rather than performing a computationally expensive non-linear least squares estimation to find $\tau_{e}$, it takes a first-order approximation of $\Psi\left(\Theta_{\mathrm{t}}, \tau_{n}\right)$ around $\tau_{n}$. Rearranging terms $\tau_{e}$ is then the coefficient vector in an OLS regression. 


$$
\begin{aligned}
& G=(T-1)\left[\frac{\sum_{t=1}^{T-1}\left(\varepsilon_{t+1} \otimes v_{t}\right)}{T-1}\right]\left[\frac{\sum_{t=1}^{T-1}\left(\varepsilon_{t+1} \otimes v_{t}\right)\left(\varepsilon_{t+1} \otimes v_{t}\right)^{\prime}}{T-1}\right]^{-1} \times \\
& {\left[\frac{\sum_{t=1}^{T-1}\left(\varepsilon_{t+1} \otimes v_{t}\right)}{T-1}\right]}
\end{aligned}
$$

has an asymptotic $\chi^{2}$ distribution with degrees of freedom given by $4 \times m$. The vector of state variables $\Theta_{\mathrm{t}}$ is chosen for $v_{t}$.

\section{Model Parameterization}

The paper presents simulations results for four versions of the model. The first drops the riskfree asset from the analysis, focusing on the consumption-saving decision under uncertainty. The second adds the riskfree asset back in, focusing on the full consumptioninvestment decision. Comparing these two specifications the main question is: how does adding the riskfree asset change agent behavior and model characteristics. The third model augments the second specification with a simple pay-as-you-go pension system. This changes the representative agent's budget constraints in young and old working-age and retirement to:

$$
\begin{aligned}
& \left(1+n_{t}\right) c_{t}^{0}+c_{t}^{1}+s_{e t}^{1}+s_{b t}^{1}=(1-\pi) w_{t} \\
& c_{t+1}^{2}+s_{e t+1}^{2}+s_{b t+1}^{2}=(1-\pi) w_{t+1}+\left(1+r_{e t+1}\right) s_{e t}^{1}+\left(1+r_{f t}\right) s_{b t}^{1} \\
& c_{t+2}^{3}=\left(1+r_{e t+2}\right) s_{e t+1}^{2}+\left(1+r_{f t+1}\right) s_{b t+1}^{2}+\left(\frac{N_{t+1}+N_{t}}{N_{t-1}}\right) \pi w_{t+2}
\end{aligned}
$$

${ }^{12}$ The accuracy test is implemented in the following manner. Given $\tau^{*}, \gamma^{*}, \xi^{*}$, and $\omega^{*}$ at convergence, the model is simulated $N$ times, each time for different draws of the technology shock and the age distribution. For these $N$ simulations, the frequency with which the $G$ statistic is greater than the critical value of the $95^{\text {th }}$ percentile of a $\chi_{20}^{2}$ is reported. If the percentage of $G$ statistics above the critical value of the $95^{\text {th }}$ percentile is substantially greater than five percent, this is evidence against accuracy of the solution. 
where $\pi$ is the payroll tax levied on young and old workers and the last term on the righthand-side in (30) is the per capita retirement benefit. It is worth noting that the retirement benefit is not a riskfree source of income as it loads on technology via the wage. In effect this extension gives retirees access to wage income, raising the question whether their investment behavior changes as a result. A further question is whether this form of pension system protects investors from cohort-specific demographic risk. The fourth specification is based on a modification of the utility function, which is additively separable in $c_{t}{ }^{0}$ and $c_{t}{ }^{1}$. This says that young workers care about per capita rather than household consumption. Since it is not obvious whether agents' utility is separable in their consumption and that of their children specification in which young workers care about household consumption is also explored. 13

$$
V_{t}=\frac{\left(\left(2+n_{t}\right) c_{t}^{1}\right)^{1-\theta}}{1-\theta}+\beta E_{t}\left[\frac{\left(c_{t+1}^{2}\right)^{1-\theta}}{1-\theta}\right]+\beta^{2} E_{t}\left[\frac{\left(c_{t+2}^{3}\right)^{1-\theta}}{1-\theta}\right]
$$

Since (4') leaves open how to allocate household consumption between young workers and their children, it is assumed that $c_{t}{ }^{0}=c_{t}{ }^{1}$. With preferences represented by (4') equation (11) drops away while (12) and (13) are replaced by:

$$
\begin{aligned}
& \left(\left(2+n_{t}\right) c_{t}^{1}\right)^{-\theta}=\beta E_{t}\left\lfloor\left(c_{t+1}^{2}\right)^{-\theta}\left(1+r_{e t+1}\right)\right\rfloor \\
& \left(\left(2+n_{t}\right) c_{t}^{1}\right)^{-\theta}=\beta\left(1+r_{f t}\right) E_{t}\left\lfloor\left(c_{t+1}^{2}\right)^{-\theta}\right\rfloor
\end{aligned}
$$

Starting values for $w_{t}{ }^{1}$ and $w_{t}{ }^{2}$, and for $\tau, \gamma, \xi$, and $\omega$, are chosen based on a version of the model with perfect foresight, in which the representative agent makes only a consumptionsaving decision (the portfolio problem drops away). In that framework, given the

${ }^{13}$ The specification of preferences is easily extended to include a parameter at which parents discount the utility of dependent offspring. In addition the relative weight of consumption over the life cycle in (4) is constant, which could be modified by giving each period its own weight in lifetime utility.

14 The model is parameterized to reflect the fact that each period corresponds to roughly twenty years. The subjective discount rate $\beta$ is set at 0.6 , which corresponds to a pure rate of time preference $\rho$ of about 2.5 percent per year where $\beta=1 /(1+\rho)^{20}$. The coefficient of relative risk aversion $\theta$ is set at 1 so that period utility takes the form $u(c)=\ln (c)$. The share of output that is on average rewarded to capital $\alpha$ is set at 0.3 . Depreciation is assumed to occur at a rate of 2.5 percent per year so that $\delta=1-0.975^{20}=0.4$. The payroll tax rate $\pi$ is set at 0.2 in the model with social security. The stationary technology shock follows $\ln A_{t}=\phi \ln A_{t-1}+\varepsilon_{t}$ where $\phi=0, \varepsilon_{t} \sim N\left(0, \sigma_{\varepsilon}\right)$ and $\sigma_{\varepsilon}=0.1$. The period $t$ child cohort is given by $\ln N_{t}=\rho \ln N_{t-1}+v_{t}$ with $v_{t} \sim N\left(0, \sigma_{v}\right), \rho=0.99$, and $\sigma_{v}=0.01$. Period $t$ population growth is then backed out according to $N_{t}=\left(1+n_{t}\right) N_{t-1}$. These parameter choices are in line with the recent overlapping 
preference and production parameters, steady state values of the choice variables and factor returns are given in Table 2.15

Table 2: Steady State Values for the Model without Uncertainty

\begin{tabular}{lccccccccc} 
& $c_{0}=c_{1}$ & $c_{2}$ & $c_{3}$ & $s_{e}{ }^{1}$ & $s_{e}{ }^{2}$ & $K$ & $r_{e}$ & $w^{l}$ & $w^{2}$ \\
\hline$(4)$ & 0.1531 & 0.2243 & 0.3287 & 0.0153 & 0.1346 & 0.1496 & 1.4420 & 0.3216 & 0.3589 \\
$(4 S S)$ & 0.1048 & 0.1950 & 0.3628 & 0.0161 & 0.0806 & 0.0967 & 2.1009 & 0.2257 & 0.2756 \\
$\left(4^{\prime}\right)$ & 0.1539 & 0.3312 & 0.3564 & 0.0795 & 0.1987 & 0.2783 & 0.7932 & 0.3874 & 0.5300 \\
\hline
\end{tabular}

With agents' preferences described by (4) young workers consume a large fraction of their wage income, saving under five percent. Having to raise children means they postpone saving largely until old working-age. While the wage is the only source of income for young workers it makes up just under 90 percent of total income for old workers, with the remainder generated by savings from young working-age. Retirement income is generated purely out of savings with per capita retirement consumption well above that of young and old workers. Adding pay-as-you-go social security to the model reduces the need to save for retirement so that wealth accumulation by young and old workers falls. As a result the equilibrium capital stock falls, pushing the return on capital up and the wage down (the endogenous state variables $w^{l}$ and $w^{2}$ reflect after-tax income). The steady state retirement benefit amounts to 0.1129 , corresponding to a 40 percent replacement rate and a return on payroll contributions of zero since the model is stationary. Switching to (4') generates substantial capital deepening. This is because the savings rate of young workers increases to just above 20 percent when they care about household rather than per capita consumption, due to the concavity of period utility. This capital deepening makes agents better off, with lifetime income substantially above that when preferences are represented by (4).

\section{Simulation Results}

Table 3 characterizes the solution to the model based on (4) with only the consumptionsaving problem, presenting the descriptive statistics of the model. ${ }^{16}$ These are generated

generations literature. Higgins (1994) chooses $\alpha=0.33, \beta=0.54, \delta=0.72$, and $\theta=0.77$ in the context of a 3 period model. Higgins and Williamson (1996) appear to have the same parameterization, with the exception that $\theta$ is set at 1 . Attanasio and Violante (2000), in a model with mortality risk, set $\alpha=0.36, \beta=1.011$ per annum, $\delta=0.5$ per annum, and $\theta=2$.

${ }^{15}$ In the perfect foresight case, the model has only one state variable, the capital-labor ratio. Imposing the equilibrium condition that net saving equal net investment, a non-linear equation solver csolve.m written by Christopher Sims for Matlab is used to solve for the steady state.

${ }^{16}$ In this specification the two first-order conditions relating to bond holdings fall away, leaving only the conditional expectations in (12) and (15) to be parameterized. The set of period $t$ state variables remains $\Theta_{\mathrm{t}}$. 
using the coefficients on $\Theta_{\mathrm{t}}$ at convergence and simulating the model for the sequence of technology shocks and demographics used for the PEA. ${ }^{17}$ The descriptive statistics in Table 3 for the first-order approximation to conditional expectations use an approximation of the following form

$$
\Psi\left(\Theta_{t}, \tau\right)=\exp \left(\tau_{0}+\tau_{1} w_{t}^{1}+\tau_{2} w_{t}^{2}+\tau_{3} N_{t}+\tau_{4} N_{t-1}+\tau_{5} N_{t-2}\right)
$$

in the case of (12) for example. In other words the algorithm estimates six coefficients per Euler equation. Table 3 also reports simulation results based on a second-order approximation, which is based on a reduced tensor basis that omits terms of the third order and higher. In that case, the algorithm estimates 21 coefficients per parameterized expectation. Finally Table 3 reports simulation results based on a third-order approximation, again based on a reduced tensor basis that omits all terms of the fourth order and higher.

Table 3: Descriptive Statistics of the Consumption-Saving Model

\begin{tabular}{ccccccc}
\hline & \multicolumn{2}{c}{ First-Order } & \multicolumn{2}{c}{ Second-Order } & \multicolumn{2}{c}{ Third-Order } \\
& $\mu$ & $\sigma$ & $\mu$ & $\sigma$ & $\mu$ & $\sigma$ \\
\hline$c^{I}$ & 0.1527 & 0.0116 & 0.1527 & 0.0114 & 0.1527 & 0.0114 \\
$c^{2}$ & 0.2237 & 0.0177 & 0.2237 & 0.0173 & 0.2237 & 0.0173 \\
$c^{3}$ & 0.3273 & 0.0214 & 0.3274 & 0.0214 & 0.3274 & 0.0214 \\
$s_{e}{ }^{l}$ & 0.0153 & 0.0020 & 0.0153 & 0.0020 & 0.0153 & 0.0020 \\
$s_{e}{ }^{2}$ & 0.1342 & 0.0101 & 0.1342 & 0.0104 & 0.1342 & 0.0104 \\
$r_{e}$ & 1.4472 & 0.1721 & 1.4470 & 0.1716 & 1.4471 & 0.1716 \\
$w$ & 0.3207 & 0.0246 & 0.3207 & 0.0247 & 0.3207 & 0.0246 \\
$w^{2}$ & 0.3579 & 0.0278 & 0.3580 & 0.0278 & 0.3580 & 0.0277 \\
$K$ & 0.1519 & 0.0136 & 0.1520 & 0.0140 & 0.1521 & 0.0141 \\
$L$ & 2.0326 & 0.0892 & 2.0326 & 0.0892 & 2.0326 & 0.0892 \\
\hline Score & \multicolumn{3}{c}{$6.9 \%$} & \multicolumn{3}{c}{$5.6 \%$} \\
\hline
\end{tabular}

The results in Table 3 do not differ perceptibly from the steady state values of the perfect foresight framework. Young workers consume a large fraction of their wage income, saving just under five percent on average. Saving for retirement is postponed until old working-age when agents save just under forty percent of total income. It is also clear that the linear approximation to expectations performs well, with model characteristics barely changing

${ }^{17}$ The values for $\tau, \gamma, \xi$, and $\omega$ are taken to have converged when $\left(\tau_{n}-\tau_{e}\right) / \tau_{n},\left(\gamma_{n}-\gamma_{e}\right) / \gamma_{n},\left(\xi_{n}\right.$ $\left.-\xi_{e}\right) / \xi_{n}$, and $\left(\omega_{n}-\omega_{e}\right) / \omega_{n}$ are each less than 0.00001 .

18 To generate the PEA solution to the model the sequences for technology and the age distribution are drawn for length $T=1000$. The same draws are used across specifications for easier comparison. The results remain qualitatively unchanged for sequences of much greater length. 
when moving to higher order approximations. The score statistic, the percentage of $G$ statistics for 500 simulations that are above the critical value of the $95^{\text {th }}$ percentile of a $\chi_{10}{ }^{2}$ distribution, indicates that the first order approximation is successful in fitting expectations and that gains from higher order approximations are small. The formation of expectations appears to be largely linear in $\Theta_{\mathrm{t}}$. Table 4 reports the correlations matrix associated with the third-order approximation results reported in table 3:

Table 4: Correlations based on Third-Order Approximation

\begin{tabular}{ccccccc}
\hline & $c^{1}$ & $c^{2}$ & $c^{3}$ & $r_{e}$ & $w$ & $w^{2}$ \\
$c^{1}$ &. & 0.9943 & 0.9684 & 0.5235 & 0.9977 & 0.9943 \\
$c^{2}$ &. &. & 0.9827 & 0.4687 & 0.9951 & 0.9999 \\
$c^{3}$ &. &. &. & 0.3433 & 0.9688 & 0.9827 \\
$r_{e}$ &. &. &. &. & 0.5351 & 0.4686 \\
$w$ &. &. &. &. &. & 0.9951 \\
$w^{2}$ &. &. &. &. &. &. \\
\hline
\end{tabular}

Table 4 shows that the correlation between wage income and returns on capital is positive as expected given the Cobb-Douglas production technology. Yet the degree of correlation is far from perfect. Young workers would like to hold more equity because the low degree of correlation offers a measure of diversification against technology shocks. However their ability to accumulate capital is limited so that the correlation between wage income and total income to old workers is almost perfect. 
Table 5 reports the descriptive statistics for the full consumption-investment problem. The first, second, and third-order approximations to the conditional expectations correspond to those discussed above.

Table 5: Descriptive Statistics of the Consumption-Investment Model

\begin{tabular}{ccccccc}
\hline & \multicolumn{2}{c}{ First-Order } & \multicolumn{2}{c}{ Second-Order } & \multicolumn{2}{c}{ Third-Order } \\
& $\mu$ & $\sigma$ & $\mu$ & $\sigma$ & $\mu$ & $\sigma$ \\
\hline$c^{l}$ & 0.1529 & 0.0117 & 0.1532 & 0.0129 & 0.1531 & 0.0127 \\
$c^{2}$ & 0.2248 & 0.0274 & 0.2250 & 0.0280 & 0.2248 & 0.0268 \\
$c^{3}$ & 0.3271 & 0.0242 & 0.3271 & 0.0261 & 0.3270 & 0.0218 \\
$s_{e}{ }^{l}$ & 0.0949 & 0.0063 & 0.1449 & 0.0170 & 0.1413 & 0.0167 \\
$s_{e}{ }^{2}$ & 0.0556 & 0.0137 & 0.0065 & 0.0047 & 0.0096 & 0.0044 \\
$s_{b}{ }^{2}$ & -0.0795 & 0.0052 & -0.1296 & 0.0179 & -0.1260 & 0.0168 \\
$s_{b}{ }^{2}$ & 0.0795 & 0.0048 & 0.1296 & 0.0178 & 0.1260 & 0.0168 \\
$r_{e}$ & 1.4408 & 0.1820 & 1.4375 & 0.1948 & 1.4410 & 0.1938 \\
$r_{f}$ & 1.4198 & 0.2010 & 1.4186 & 0.1727 & 1.4268 & 0.1481 \\
$w$ & 0.3213 & 0.0251 & 0.3217 & 0.0258 & 0.3214 & 0.0256 \\
$w^{2}$ & 0.3598 & 0.0391 & 0.3611 & 0.0454 & 0.3604 & 0.0431 \\
$r_{e}-r_{f}$ & 0.0210 & 0.2459 & 0.0190 & 0.1722 & 0.0142 & 0.1417 \\
$K$ & 0.1529 & 0.0150 & 0.1538 & 0.0182 & 0.1533 & 0.0177 \\
$L$ & 2.0326 & 0.0892 & 2.0326 & 0.0892 & 2.0326 & 0.0892 \\
\hline Sharpe & \multicolumn{3}{c}{0.1154} & \multicolumn{2}{c}{0.0975} & \\
Score & $39.7 \%$ & \multicolumn{3}{c}{0.0733} \\
\hline
\end{tabular}

Comparing tables 3 and 5 yields a number of insights. Introducing the riskless asset changes the pattern of asset accumulation in a fundamental way. Without the riskless asset young workers hold almost no equity because their consumption needs are large while raising children. Once the riskless asset is introduced young workers short the bond in order to invest in equity. Equity holdings of young workers rise to above forty percent of their wage income (for the second- and third-order approximations). Old workers lend to young workers because this gives them a safe income stream in retirement. By deciding to hold almost no equity they largely eliminate consumption risk in retirement.

With the introduction of the riskless asset agents act as if they are increasingly risk averse with age, although the coefficient of relative risk aversion is constant over the life cycle. Young workers short the riskless asset, investing in risky equity, while old workers hold primarily the riskfree bond. This behavior comes from the interaction of the life cycle features of the model with the risk-return characteristics of stocks and bonds. Young workers have an additional working period ahead of them so that next period consumption does not depend entirely on savings. This makes investing in high yielding but risky equity attractive, especially since labor and interest income are imperfectly correlated. But since consumption requirements for young workers are high they must borrow to hold shares of ownership in capital, generating supply of the riskless asset. In contrast old workers' retirement consumption depends entirely on savings. Faced with the choice of investing in risky equity 
or safe bonds they hold bonds almost exclusively, generating demand for the riskless asset. Minimizing consumption risk in retirement dominates old workers' portfolio decision.

The annualized return on capital in the model is about 4.56 percent. The introduction of the riskless asset produces slight capital deepening because old workers do not divest themselves entirely of equity. The annualized return on the riskfree asset amounts to 4.53 percent so that the model fails to generate an equity premium of the order observed historically in the US and other developed markets. One reason for this is that the shares of ownership in capital do not correspond to equity as it is commonly understood since equity in the model is not a levered asset (there are no corporate bonds). The return on capital going to shareholders in the model should be thought of as subsuming equity, corporate bonds, and other forms of lending and ownership. Though the implications for asset returns are not of the order observed in the data, the Sharpe ratio supported by the model is around ten percent, an order of magnitude comparable to Storesletten, Telmer, and Yaron (1997). This result is encouraging since the model features only aggregate uncertainty, while the model of Storesletten, Telmer, and Yaron includes persistent agent-specific shocks. The Sharpe ratio benchmark associated with Mehra and Prescott (1985) is 37 percent.

With agents making the full consumption-investment decision expectations become nonlinear in $\Theta_{\mathrm{t}}$. While the score statistic improves only marginally when going from the first- to a second-order approximation without the riskless asset, it improves by a factor of five when going from the first- to a second-order approximation and differences in portfolio allocation between young and old workers become more pronounced. Looking to the third-order approximation it appears that the key non-linearity in the formation of expectations is captured by second-order terms. Table 6 presents the correlations matrix associated with Table 5:

Table 6: Correlations based on Third-Order Approximation using (4)

\begin{tabular}{ccccccccc}
\hline & $c^{I}$ & $c^{2}$ & $c^{3}$ & $r_{f}$ & $r_{e}$ & $w$ & $w^{2}$ & $r_{e}-r_{f}$ \\
$c^{1}$ &. & 0.9740 & 0.4186 & -0.3532 & 0.3693 & 0.9964 & 0.9759 & 0.8742 \\
$c^{2}$ &. &. & 0.2291 & -0.2225 & 0.5191 & 0.9640 & 0.9994 & 0.9426 \\
$c^{3}$ &. &. &. & -0.7965 & -0.6084 & 0.4665 & 0.2312 & 0.0001 \\
$r_{f}$ &. &. &. &. & 0.6867 & -0.3829 & -0.2237 & -0.1057 \\
$r_{e}$ &. &. &. &. &. & 0.3297 & 0.5182 & 0.6503 \\
$w$ &. &. &. &. &. &. & 0.9651 & 0.8512 \\
$w^{2}$ &. &. &. &. &. &. &. & 0.9427 \\
$r_{e}-r_{f}$ &. &. &. &. &. &. &. &. \\
\hline
\end{tabular}

Table 6 illustrates the benefits to young workers of being able to borrow and hold equity. The correlation of consumption with wage income in old working-age falls relative to the model without bonds. And while the correlation of retirement consumption with the return on capital is 0.3433 in the absence of the riskless asset, it is -0.6084 in the consumptioninvestment framework. Essentially agents have eliminated their exposure to technology shocks by holding mostly the riskless asset. Table 6 also illustrates that the riskfree rate and 
the return on equity tend to move together, because effects related to changes in aggregate saving dominate effects that drive returns on both assets in opposite directions.

Table 7 reports the descriptive statistics of the consumption-investment model augmented with pay-as-you-go social security. The first, second, and third-order approximations to the conditional expectations are as above.

Table 7: Descriptive Statistics of the Consumption-Investment Model with Social Security

\begin{tabular}{ccccccc}
\hline & \multicolumn{2}{c}{ First-Order } & \multicolumn{2}{c}{ Second-Order } & \multicolumn{2}{c}{ Third-Order } \\
& $\mu$ & $\sigma$ & $\mu$ & $\sigma$ & $\mu$ & $\sigma$ \\
\hline$c^{l}$ & 0.1045 & 0.0081 & 0.1046 & 0.0088 & 0.1046 & 0.0088 \\
$c^{2}$ & 0.1948 & 0.0192 & 0.1953 & 0.0230 & 0.1952 & 0.0235 \\
$c^{3}$ & 0.3613 & 0.0239 & 0.3612 & 0.0239 & 0.3611 & 0.0241 \\
$s_{e}{ }^{l}$ & 0.0462 & 0.0040 & 0.0918 & 0.0105 & 0.0929 & 0.0118 \\
$s_{e}{ }^{2}$ & 0.0504 & 0.0072 & 0.0054 & 0.0022 & 0.0042 & 0.0030 \\
$s_{b}{ }^{l}$ & -0.0301 & 0.0031 & -0.0758 & 0.0104 & -0.0769 & 0.0116 \\
$s_{b}{ }^{2}$ & 0.0301 & 0.0030 & 0.0758 & 0.0104 & 0.0769 & 0.0116 \\
$r_{e}$ & 2.1097 & 0.2448 & 2.1060 & 0.2656 & 2.1080 & 0.2701 \\
$r_{f}$ & 2.0905 & 0.2084 & 2.0850 & 0.1943 & 2.0824 & 0.2425 \\
$w$ & 0.2813 & 0.0219 & 0.2816 & 0.0225 & 0.2815 & 0.0226 \\
$w^{2}$ & 0.2753 & 0.0259 & 0.2765 & 0.0335 & 0.2764 & 0.0342 \\
$b$ & 0.1125 & 0.0089 & 0.1127 & 0.0091 & 0.1126 & 0.0091 \\
$r_{e}-r_{f}$ & 0.0192 & 0.2876 & 0.0210 & 0.1956 & 0.0256 & 0.2412 \\
$K$ & 0.0982 & 0.0094 & 0.0987 & 0.0116 & 0.0986 & 0.0118 \\
$L$ & 2.0326 & 0.0892 & 2.0326 & 0.0892 & 2.0326 & 0.0892 \\
\hline Sharpe & \multicolumn{6}{c}{0.0784} \\
Score & $29.8 \%$ & \multicolumn{2}{c}{0.0791} & & 0.0948 \\
\hline
\end{tabular}

Portfolio behavior of the representative agent does not change qualitatively with the introduction of the pay-as-you-go pension system. Investors still shift financial wealth from stocks to bonds as they grow older, possibly because the retirement benefit is not riskfree. If this is the case it underlines how important consumption risk in retirement is for old workers. Of course this finding is conditional on the nature of the retirement benefit. If the benefit were riskfree, there might be substantial repercussions for portfolio behavior. Table 8 presents the correlations matrix for the model with social security: 
Table 8: Correlations based on Third-Order Approximation

\begin{tabular}{ccccccccc}
\hline & $c^{l}$ & $c^{2}$ & $c^{3}$ & $r_{f}$ & $r_{e}$ & $w$ & $b$ & $r_{e}-r_{f}$ \\
$c^{l}$ & $\cdot$ & 0.9648 & 0.6852 & -0.3444 & 0.3683 & 0.9960 & 0.9858 & 0.8423 \\
$c^{2}$ &. &. & 0.4925 & -0.1883 & 0.5479 & 0.9478 & 0.9420 & 0.9311 \\
$c^{3}$ &. &. &. & -0.7278 & -0.3399 & 0.7333 & 0.7434 & 0.2616 \\
$r_{f}$ &. &. &. &. & 0.6786 & -0.3852 & -0.3640 & -0.0720 \\
$r_{e}$ &. &. &. &. &. & 0.3160 & 0.3252 & 0.8032 \\
$w$ &. &. &. &. &. &. & 0.9899 & 0.8119 \\
$b$ &. &. &. &. &. &. &. & 0.8032 \\
$r_{e}-r_{f}$ &. &. &. &. &. &. &. &. \\
\hline
\end{tabular}

Though the per capita retirement benefit is negatively correlated with the return on the riskless asset, it loads on two factors: technology and the number of workers per retiree. This makes it possible that baby boomers who have few children may in fact receive a low per capita benefit because the workforce is relatively small when they retire. Adding social security leaves the risk-return characteristics of the model broadly unchanged, the smaller capital stock aside. The Sharpe ratio supported by the model remains around ten percent. The non-linearity in expectations appears to be captured by the second-order approximation, as the score statistic improves only marginally when adding third-order terms.

Table 9 reports the descriptive statistics of the consumption-investment model with young workers deriving utility from household consumption. The first, second, and third-order approximations to conditional expectations are as above.

Table 9: Descriptive Statistics of the Consumption-Investment Model using (4')

\begin{tabular}{ccccccc}
\hline & \multicolumn{2}{c}{ First-Order } & \multicolumn{2}{c}{ Second-Order } & \multicolumn{2}{c}{ Third-Order } \\
& $\mu$ & $\sigma$ & $\mu$ & $\sigma$ & $\mu$ & $\sigma$ \\
\hline$c^{l}$ & 0.1533 & 0.0112 & 0.1535 & 0.0119 & 0.1535 & 0.0119 \\
$c^{2}$ & 0.3306 & 0.0298 & 0.3310 & 0.0331 & 0.3311 & 0.0340 \\
$c^{3}$ & 0.3551 & 0.0198 & 0.3550 & 0.0211 & 0.3550 & 0.0217 \\
$s_{e}{ }^{l}$ & 0.1531 & 0.0082 & 0.2594 & 0.0269 & 0.2735 & 0.0272 \\
$s_{e}{ }^{2}$ & 0.1248 & 0.0196 & 0.0196 & 0.0094 & 0.0057 & 0.0066 \\
$s_{b}{ }^{2}$ & -0.0736 & 0.0077 & -0.1797 & 0.0212 & -0.1939 & 0.0210 \\
$s_{b}{ }^{2}$ & 0.0736 & 0.0074 & 0.1798 & 0.0212 & 0.1939 & 0.0211 \\
$r_{e}$ & 0.7969 & 0.1120 & 0.7954 & 0.1182 & 0.7948 & 0.1188 \\
$r_{f}$ & 0.7906 & 0.0906 & 0.7881 & 0.0863 & 0.7865 & 0.0845 \\
$w$ & 0.3862 & 0.0297 & 0.3866 & 0.0303 & 0.3867 & 0.0303 \\
$w^{2}$ & 0.5290 & 0.0448 & 0.5303 & 0.0533 & 0.5307 & 0.0545 \\
$r_{e}-r_{f}$ & 0.0063 & 0.1162 & 0.0073 & 0.0916 & 0.0084 & 0.0916 \\
$K$ & 0.2824 & 0.0258 & 0.2835 & 0.0297 & 0.2837 & 0.0299 \\
$L$ & 2.0326 & 0.0892 & 2.0326 & 0.0892 & 2.0326 & 0.0892 \\
\hline Sharpe & 0.0563 & \multicolumn{2}{c}{0.0618} & & 0.0707 \\
Score & $36.4 \%$ & \multicolumn{3}{c}{$7.5 \%$} & & \\
\hline
\end{tabular}


Changing the way young workers think about their offspring relative to themselves leaves agent behavior unchanged. Young workers short the riskless asset in order to hold equity. Old workers are willing lenders because this allows them to almost eliminate their exposure to technology shocks in retirement. The key feature of the model, that agents make portfolio decisions as though they are increasingly risk averse with age, continues to hold when preferences are described by (4'). Capital deepening aside, the risk-return characteristics of the model are broadly stable. Though the average return differential between stocks and bonds falls, the Sharpe ratio is roughly unchanged, approaching ten percent for the thirdorder approximation. The non-linearity in expectations appears to be captured by the secondorder approximation, as the score statistic improves only marginally when adding third-order terms. Table 10 presents the correlations matrix associated with Table 9:

Table 10: Correlations based on the Third-Order Approximation

\begin{tabular}{ccccccccc}
\hline & $c^{l}$ & $c^{2}$ & $c^{3}$ & $r_{f}$ & $r_{e}$ & $w$ & $w^{2}$ & $r_{e}-r_{f}$ \\
$c^{1}$ &. & 0.9921 & 0.3850 & -0.3541 & 0.4267 & 0.9975 & 0.9918 & 0.8800 \\
$c^{2}$ &. &. & 0.3067 & -0.3213 & 0.4825 & 0.9916 & 0.9998 & 0.9221 \\
$c^{3}$ &. &. &. & -0.8165 & -0.6153 & 0.3994 & 0.3081 & -0.0448 \\
$r_{f}$ &. &. &. &. & 0.6406 & -0.3596 & -0.3218 & -0.0916 \\
$r_{e}$ &. &. &. &. &. & 0.4173 & 0.4821 & 0.7060 \\
$w$ &. &. &. &. &. &. & 0.9918 & 0.8729 \\
$w^{2}$ &. &. &. &. &. &. &. & 0.9220 \\
$r_{e}-r_{f}$ &. &. &. &. &. &. &. &. \\
\hline
\end{tabular}

Across specifications a number of stylized facts emerge. With the introduction of the riskless asset, agents short the bond when young in order to invest in risky equity. Old workers are willing lenders because they want to minimize consumption risk in retirement. In short, the investment horizon matters, with agents making portfolio decisions as if they are increasingly risk averse with age. This feature of the model is robust to changes in preferences or adding a pay-as-you-go pension scheme. In addition the asset market characteristics of the model are stable across specifications.

\section{Simulating a Baby Boom-Baby Bust}

This section explores the implications of historical and projected population trends for asset returns. Figure 1 plots annualized cohort growth rates for North America (NA), the European Union (EU) and a combined region for the period 1950 to 2150, illustrating the impact of the post-war baby boom and bust. In the 20 year period centered around 1950 annualized

${ }^{19}$ For the period 1950 to 1990 the data are taken from the United Nations "World Population Prospects: The 1992 Revision," which provides data on the age distribution (in 5 year agegroups) for a large cross-section of countries. The demographic data from 1995 onward are imputed using country-specific cohort growth rates (for the same 5 year age-groups) from the World Bank "World Population Projections: The 1994-95 Edition," using the United Nations 
cohort growth in NA amounted to 0.5 percent, 0.6 percent in the EU, and 0.6 percent in the combined region. In the period centered around 1970, the peak of the baby boom, cohort growth rose to just under 2 percent per year in NA and just under 1 percent in the EU, for a growth rate of about 1.3 percent in the combined region. In the period around 1990, the peak of the baby bust, cohort growth turns negative. It is -0.7 percent per annum in NA, -0.9 percent in the EU, and -0.8 percent in the combined region. In the period around 2010 cohort growth remains negative in the EU ( -0.7 percent per year) but rebounds to 0.2 percent in NA, for an average of -0.2 percent in the combined region. Cohort growth in the very long run is zero in both regions, a feature of the World Bank population projections that should be interpreted as an "equilibrium condition" rather than forecast.

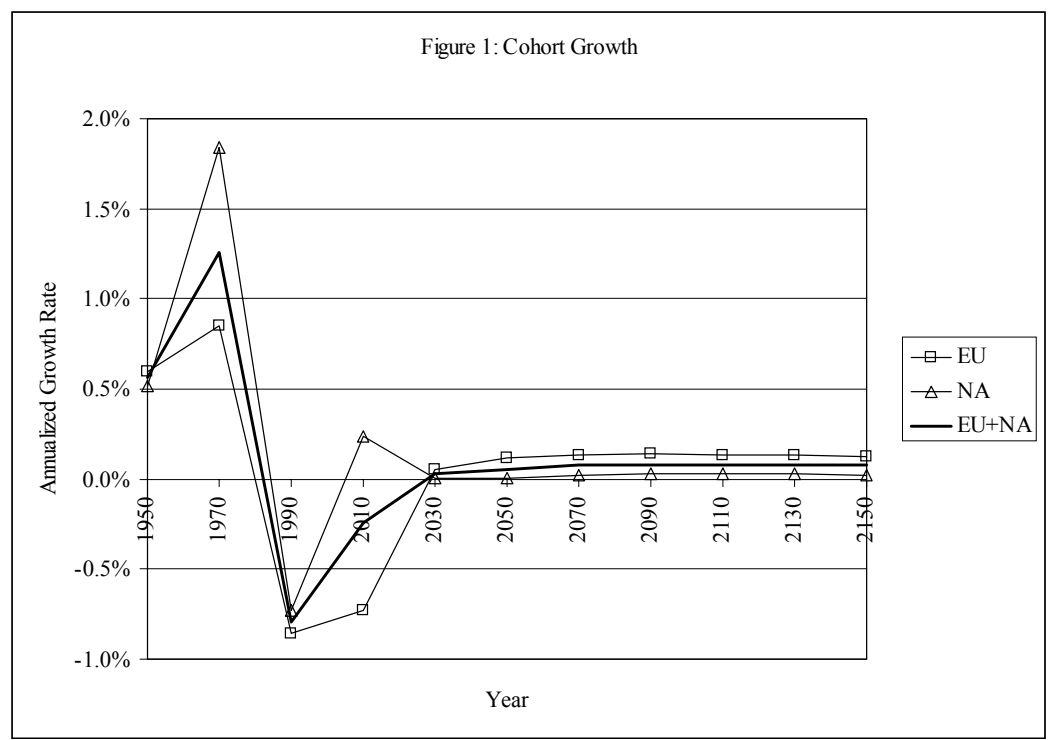

The simulated baby boom and bust differs in several respects from historical and projected population trends. The simulated transition assumes that cohort growth in equilibrium is zero. The baby boom begins in 1950 when cohort growth rises to three percent per period $(0.15$ percent on an annualized basis) and lasts until 1970 when period cohort growth is again three percent. The baby bust begins in 1990 when cohort growth is negative at -3 percent per period and lasts until 2010 when period cohort growth is again -3 percent. Thereafter cohort growth is again in equilibrium at zero.

This demographic shift is stationary (and symmetric) since population size before and after the transition are the same. As a result the focus is purely on the transitional dynamics, not on

data as a base. This data splice is necessary because the United Nations projections go only to 2025, while the World Bank data goes back only to 1990. In 1990, the base year for the projections, the data from both sources are very similar. Cohort growth rates are generated by aggregating the 5-year age groups in the original data into 20-year age groups that span 0-19, 20-39, 40-59, 60+. Cohort growth is then the growth rate of the "child" cohort over the "young worker" cohort over a 20 year interval. 
the observed fertility decline and associated capital deepening effects. 0 The shock also appears small in absolute terms compared with observed and projected population trends. However the simulated shock is large relative to $\sigma_{v}=0.01$, which corresponds to the standard deviation of US cohort growth prior to 1950. Finally the boom and bust in the simulated transition last for two periods each. As a result the simulation will have cohorts that are early baby boomers, and cohorts that are in the tail-end of the baby boom.

Figure 2 plots cohorts growth rates over the simulated transition, while Figure 3 plots the age shares.
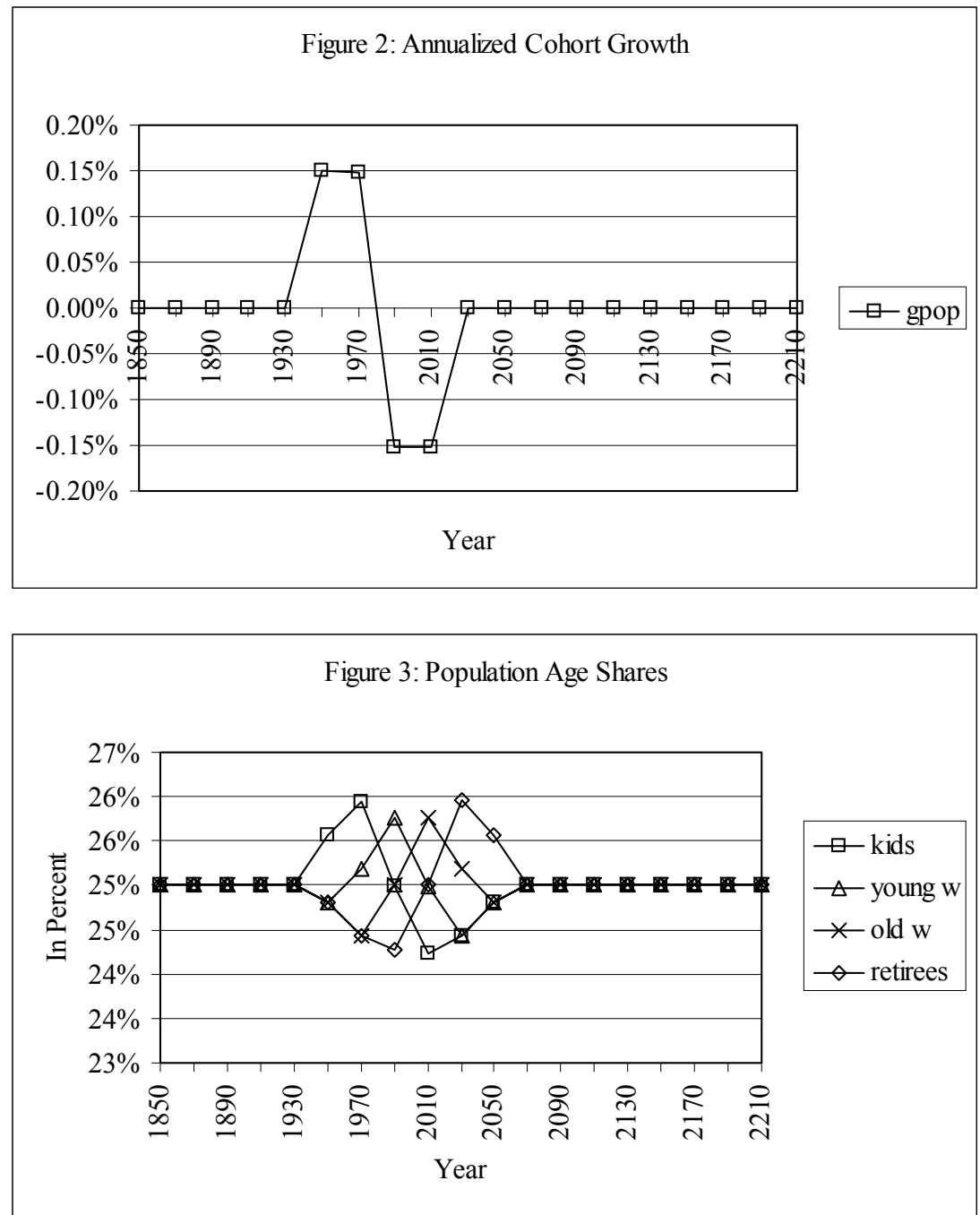

${ }^{20}$ Cohort growth rates in 1910 and 1930 were 26 and 21 percent respectively in the US. Meanwhile the Wold Bank projections suggest that cohort growth will reach zero around 2030. 
Beginning with the baseline model summarized in Table 5,Figure 4 presents annualized returns on capital and the riskless asset over the transition. 21 Returns on capital and the riskless asset move broadly together, rising during the early stages of the boom when relatively large cohorts of children push up aggregate consumption, reducing aggregate saving. Once boomer cohorts enter the workforce, aggregate saving rises, an effect that is reinforced as boom turns to bust and consumption of children becomes relatively less important.

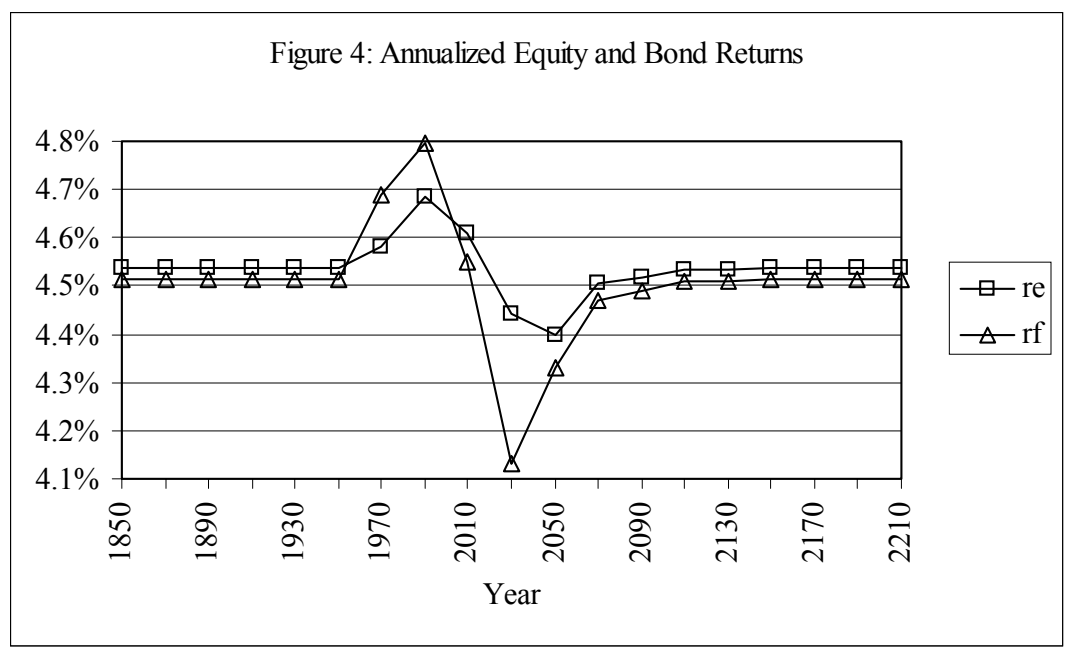

Figure 4 thus illustrates that demographic shifts lead to changes in aggregate saving over time, causing the real interest rate to vary. As the real interest rate changes it pushes returns on stocks and bonds in the same direction. The movement in returns on the risky asset are mirrored in wage income, which moves inversely with the size of the labor force. This reflects changes in the capital-labor ratio, which falls during the boom stage of the transition and rises during the bust, even though capital formation is endogenous to the model. 22 Figure 5 presents wage income over the shift. Boomer cohorts receive lower wage income than in equilibrium.

${ }^{21}$ The simulations are based on the PEA solution, using third-order approximations to parameterize expectations. Rather than allowing the technology shock to vary randomly, as is the case when the model is solved, the technology shock is now held fixed at one, in essence holding all non-demographic fundamentals constant.

${ }^{22}$ This result is robust for $\theta=2$ and $\theta=0.5$. 

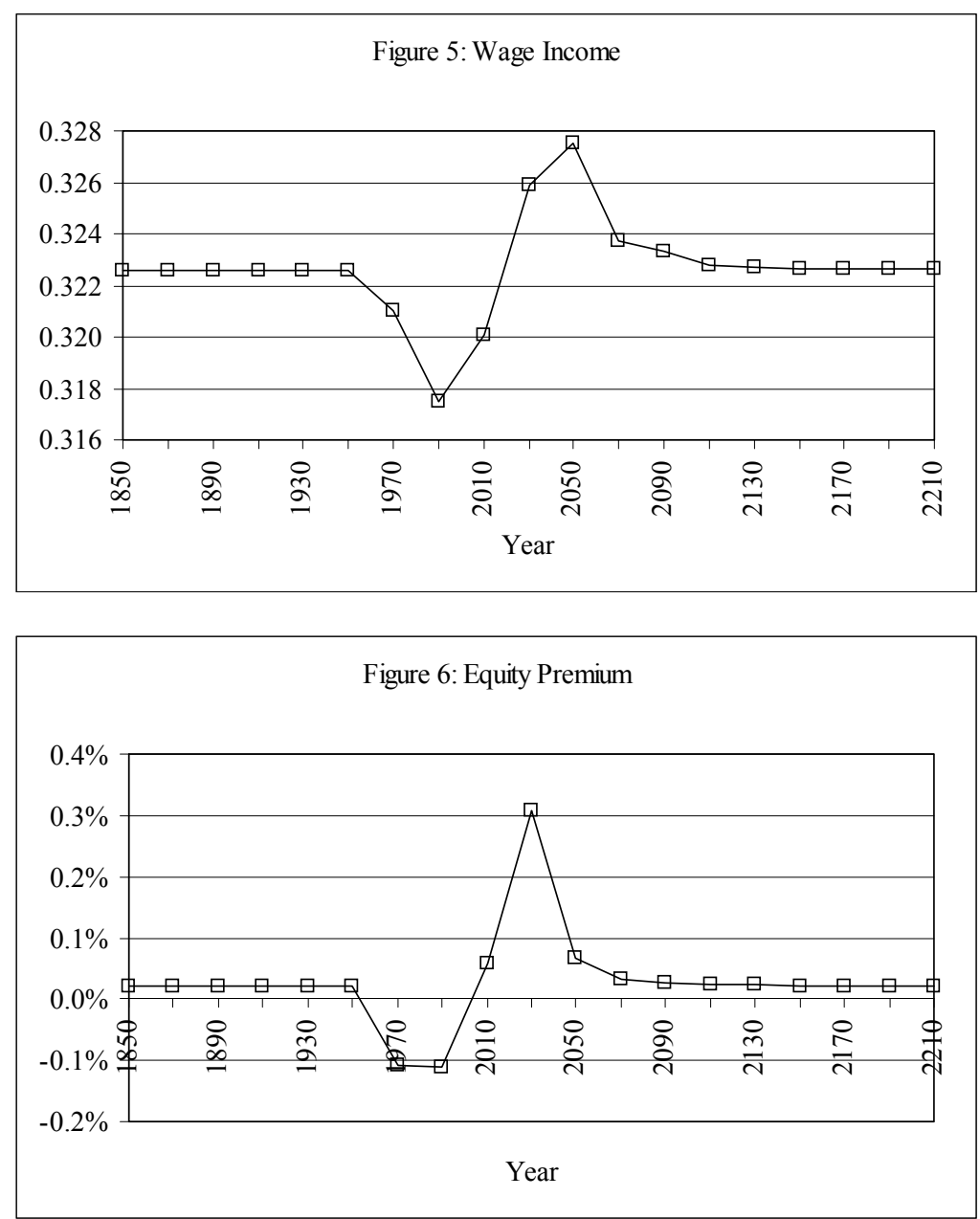

Figure 6 plots the equity premium over the transition. It falls sharply in period 1970, remaining low in 1990, then rises and peaks in 2030, before returning to its stochastic steady state around 2070. This path for the return differential stems from the interaction of agent behavior and the demographic shock. The boom begins in period 1950 when a large cohort of children is born. Factor returns and the riskfree rate in 1950 are unaffected, determined by decisions made in period centered around 1930. As a result per capita consumption of young workers falls as they feed a relatively large cohort of children, as seen in Figure 7.

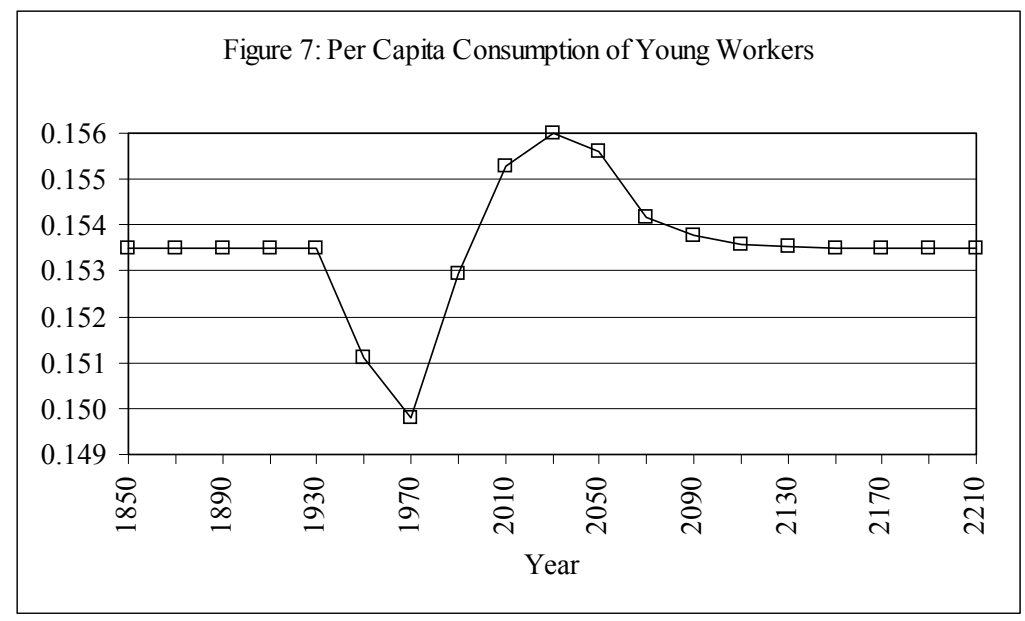


Portfolio behavior of young workers in 1950 reflects their large household consumption requirement. In addition the expected return on capital in 1970 is above steady state, because of downward pressure on the capital-labor ratio as baby boomers enter the workforce. As a result young workers want to borrow more. Although old workers want to reduce their exposure to the technology shock in retirement, young workers' increased desire to borrow results in excess supply of the riskless asset, driving its return up relative to the return on capital. The equity premium in 1970 turns negative.
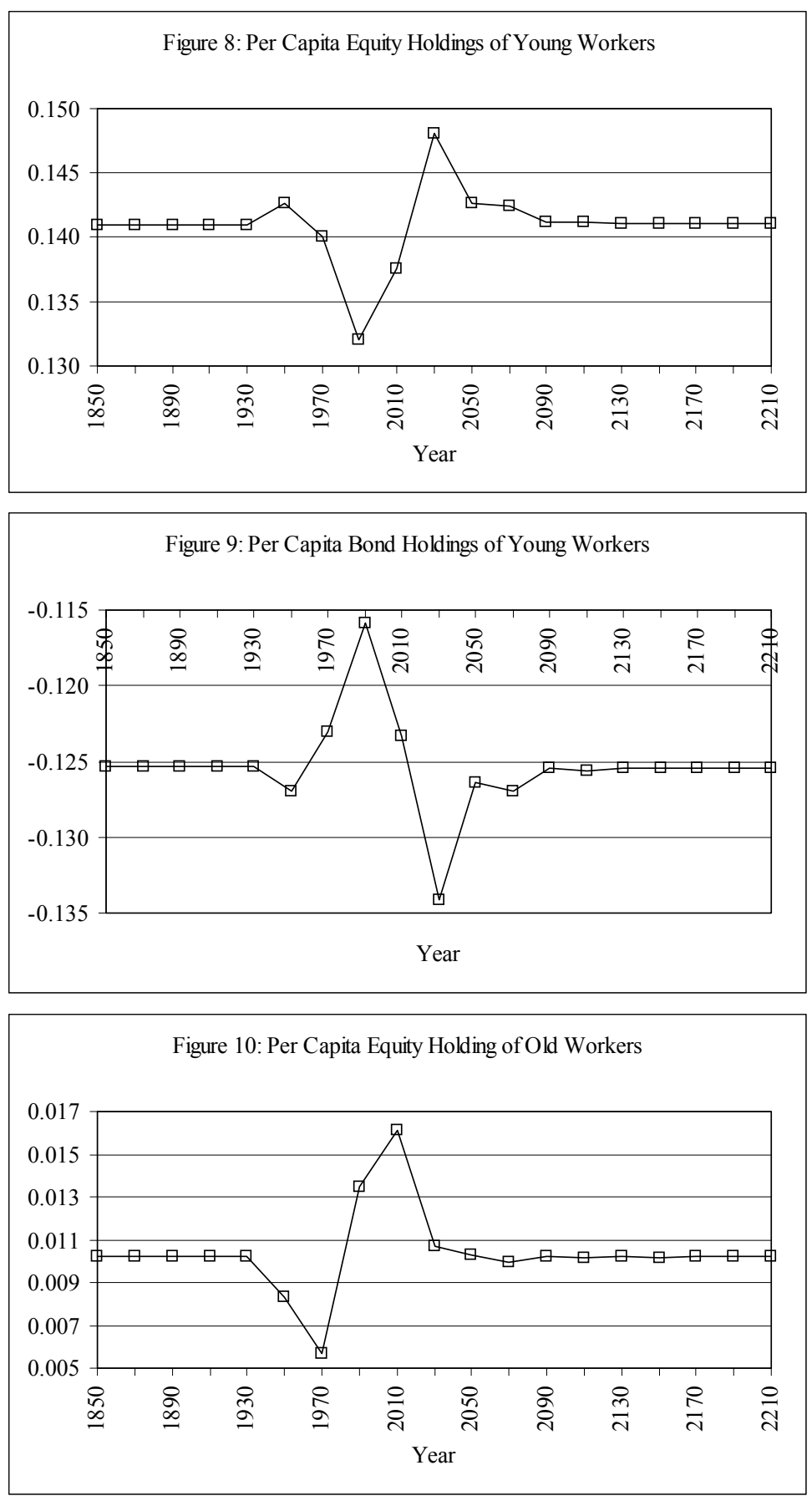


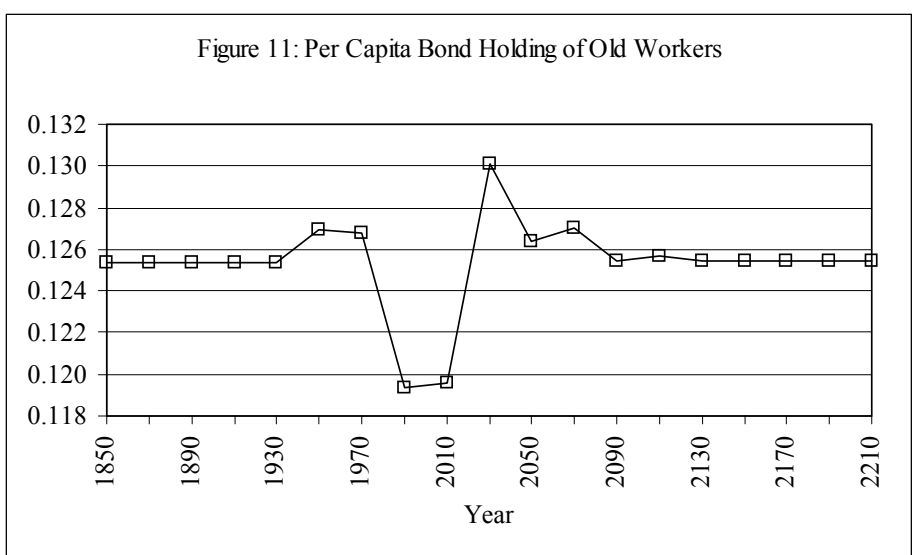

1970 brings investor behavior very similar to that in 1950 . Young workers again have a large cohort of children to feed, which reduces per capita consumption. But there is an important difference, which is illustrated in Figure 12.

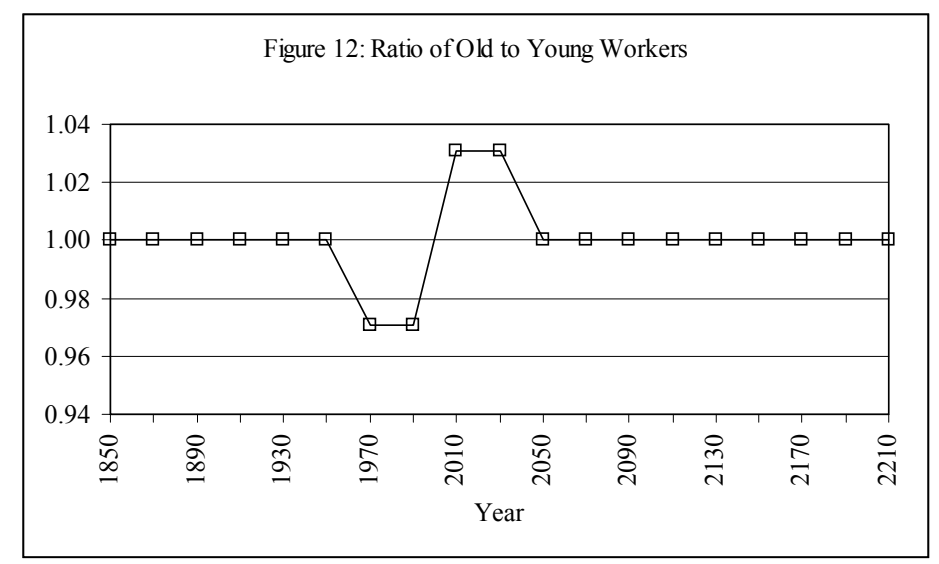

Whereas in 1950 the ratio of old to young workers is in equilibrium, the cohort of young workers in 1970 (the first boomer cohort) is larger than the cohort of old workers. This demographic imbalance exacerbates the effect of the increased desire to borrow by young workers, pushing the riskfree rate up further in 1990 relative to the return on capital. The return differential thus falls even further. Investor behavior changes dramatically in 1990, the first period of the baby bust. The cohort of young workers (the second boomer cohort) has a small number of children (the first cohort of the baby bust). As a result, per capita consumption of young workers shoots up in 1990 as illustrated by Figure 7. The repercussions for portfolio behavior of young workers are significant. They scale back equity holdings, partly because they are already well off in utility terms, but also because an increase in aggregate saving is having a downward effect on the return of capital. As a result, their borrowing in the riskfree asset falls significantly relative to equilibrium, forcing old workers in 1990 to hold more equity than they would like. This raises the return differential in 2010, with excess demand for the riskfree asset pushing down its return relative to the return on capital. 2010 brings the turning point in the transition, as can be seen from Figure 12. It is in this period that the first baby bust cohort of young workers faces off against the last of the boomer cohorts in old working-age. Although equity and bond holdings of young workers in 2010 are close to steady state levels, the demographic imbalance means that, in per capita terms, old workers are forced to hold more equity than they would like, since aggregate supply of the riskless asset is below demand. As a result the equity premium peaks in 2030. 


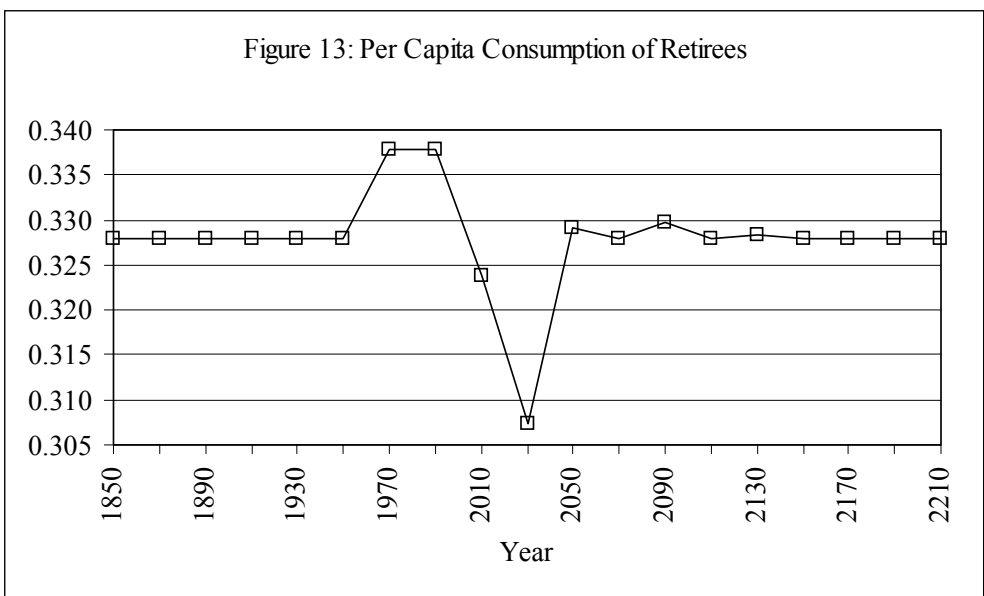

Figure 13 plots consumption of retirees. Returns on both assets are just above their steady state levels in 2010, but not sufficiently to offset other factors (low wage income and many children) that hamper the ability of the first boomer cohort to accumulate wealth. As a result, retirement consumption of the first boomer cohort is below steady state. Adverse asset market effects have a strong impact on retirement consumption of the second boomer cohort. In 2030 the decline in the bond return pushes their retirement consumption substantially below that of their parents. The situation is reversed in utility terms, however. Figure 14 plots discounted lifetime utility, evaluated at young working-age, meaning that the discounted lifetime utility of the first boomer cohort, in young working-age in 1970, is shown in 1970.

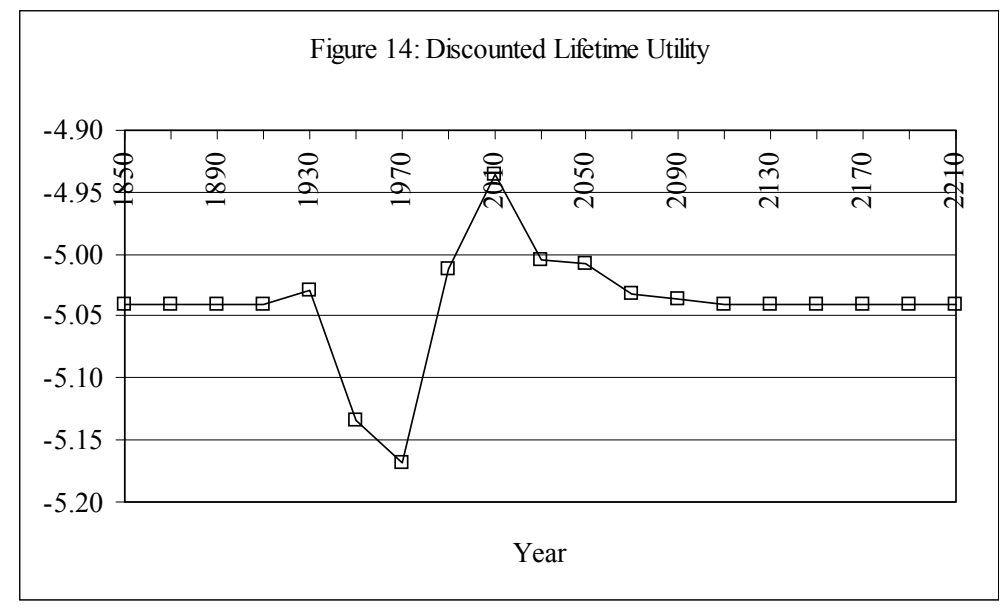

Although per capita consumption in retirement is greater for the first boomer cohort than for the second, early boomers are worse off in utility terms. This is because the first boomer cohort scales back consumption per head in young working-age because of its many children. In contrast the second boomer cohort has relatively few children so that consumption per head in young working-age is near steady state, even though wage income is significantly below. This difference has important repercussions for lifetime utility because (4) gives a greater weight to per capita consumption in young working-age than in later periods. As a result, even though the second boomer cohort has lower per capita retirement consumption than its parents, it is better off in utility terms because consumption per head in young 
working-age is higher. Thus the asset market effects of the boom-bust are second-order. The fact that raising children is costly is far more important. 23

How significant are the asset market effects? The annualized expected return on equity is 4.54 percent in equilibrium. It peaks in 1990 at 4.68 percent, bottoming out at 4.40 percent in 2050. The annualized steady state return on the riskfree asset is 4.52 percent. It peaks in 1990 at 4.8 percent, falling to 4.13 percent, its lowest level, in 2030. These effects are significant, especially for older investors who want to minimize consumption risk in retirement. The overall bond return in the 20 year period around 2030, the return to tail-end baby boomers, is 12.1 percent below equilibrium. In contrast the riskfree rate in 1990, the return to parents of the first boomer cohort, is 9.4 percent above equilibrium. 24 These effects are also significant relative to other sources of uncertainty. The largest change in the return on capital, the decline going from 2010 to 2030, amounts to 40 percent of the standard deviation of the period return (see Table 5).

Adding the pay-as-you-go pension scheme to the model leaves its key features unchanged (see Table 7). Agents still shift financial wealth from stocks to bonds as they age, even though they receive an income stream in retirement that is independent of savings. Figure 15 plots the wage over the boom-bust for the model with social security.

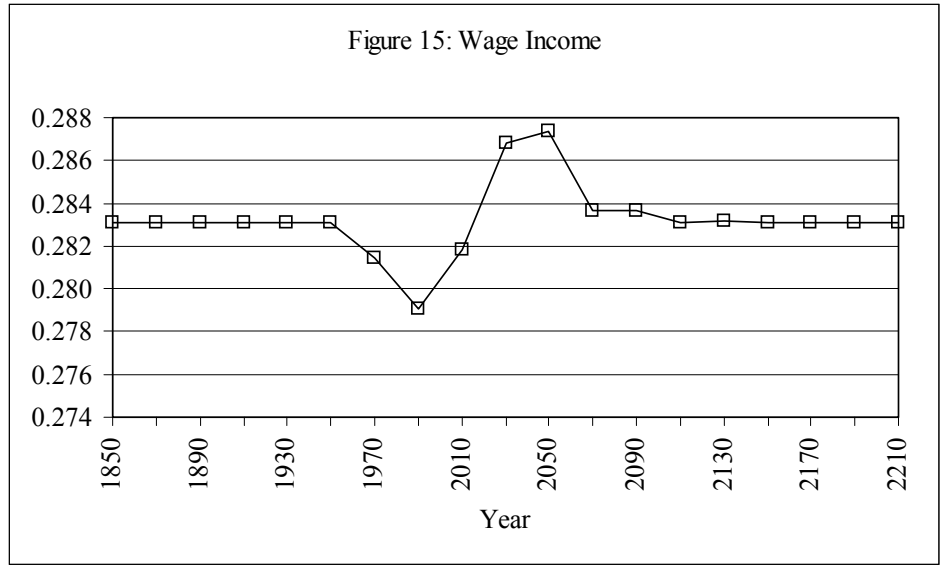

${ }^{23}$ This result highlights an omission of the model, which does not model the decision to have children. If agents derive happiness from having children, this welfare result might well be reversed.

${ }^{24}$ It is worth noting that the effect on stock returns is small compared to the run-up in stock prices over the past 20 years. The average real return on the Ibbotson Associates large stock index from 1979 - 1998 is 13.43 percent, relative to 3.53 percent for the period 1959 - 1978 . In comparison the 1990 model return on capital is only 4.8 percent above steady state. Changes in the age distribution are thus an insufficient explanation for the recent surge in stock prices. Of course this simulation exercise ignores changes in other fundamentals (the technology shock is fixed at its mean value), or the possibility of a speculative bubble. 
The wage is substantially above its steady state level in 2030, in contrast to the riskfree rate. As such the pay-as-you-go pension system could insure agents against cohort specific asset market effects. However it fails to do so because the per capita retirement benefit depends on the number of workers per retiree, a measure that falls to its lowest level in 2030 as seen in Figure 16.

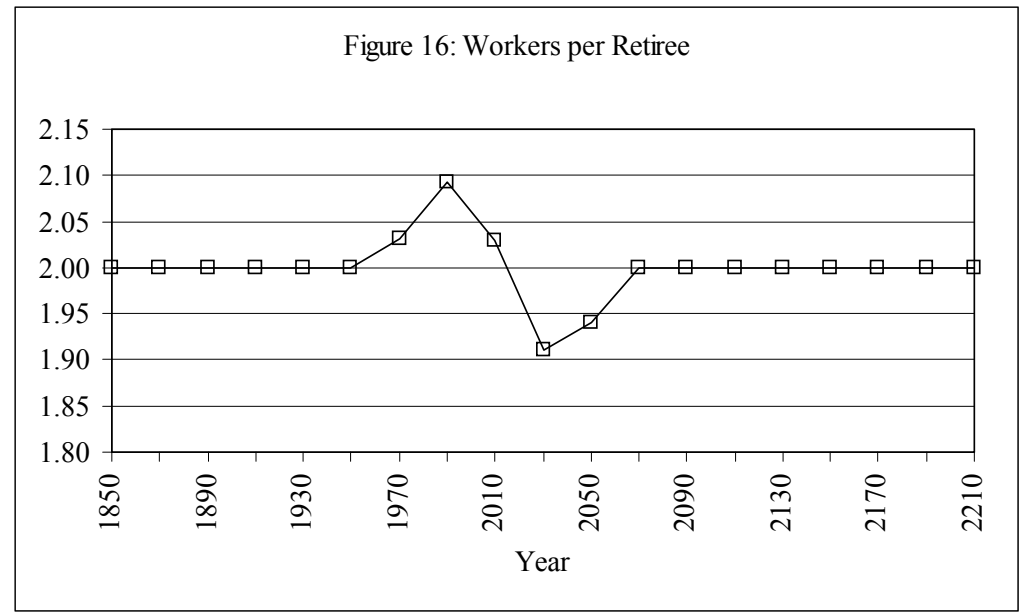

As a result the per capita retirement benefit falls to its lowest level in 2030 since the decline in the number of workers per retiree far outweighs the effect of the higher wage. This can be seen in Figure 17.

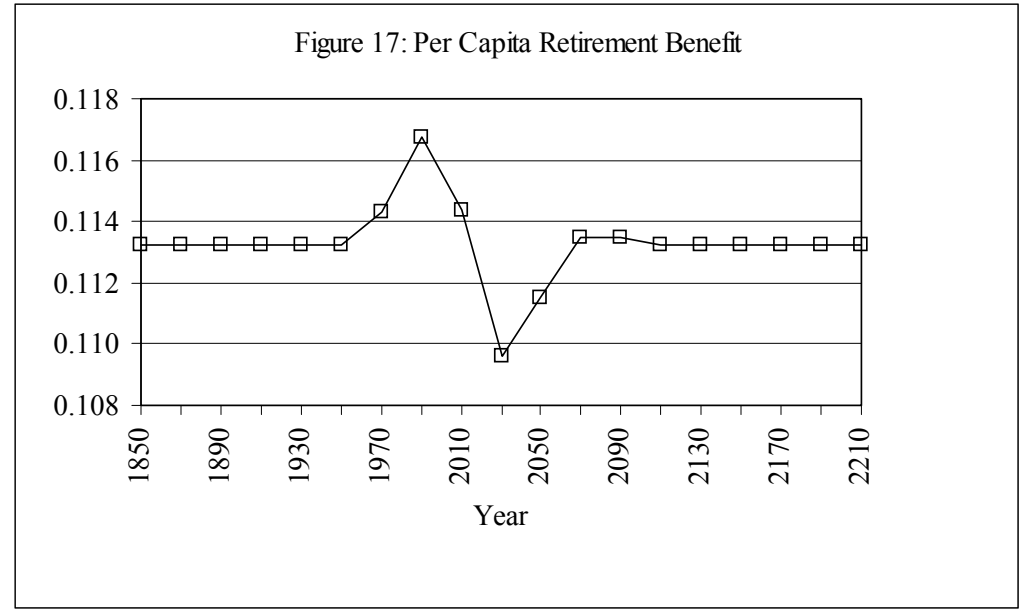

This simple pay-as-you-go pension scheme fails to insure agents against cohort-specific asset market effects that are tied to demographics, because the same demographic imbalance that pushes down the bond return in 2030 also reduces the per capita retirement benefit. Within this closed economy framework, the model thus highlights how to insure agents against asset market effects of demographic shifts: an infinitely-lived agent that varies the supply of debt in order to smooth the path of the riskfree rate. In essence this would amount to making 
transfers of wealth across generations. A government acting in this way would reflect a political consensus that it should insure agents against cohort-specific risk.

Why insure agents against adverse asset market effects if these effects are second-order? As noted above using (4) to represent lifetime utility assigns a greater weight to per capita consumption in young working-age than later periods. Rewriting young workers' utility in terms of household consumption, using (4'), leaves the asset market implications of the model unchanged but reverses the welfare result. Figure 18 plots returns on stocks and bonds, Figure 19 plots the wage, and Figure 20 plots the equity premium over the boom-bust.
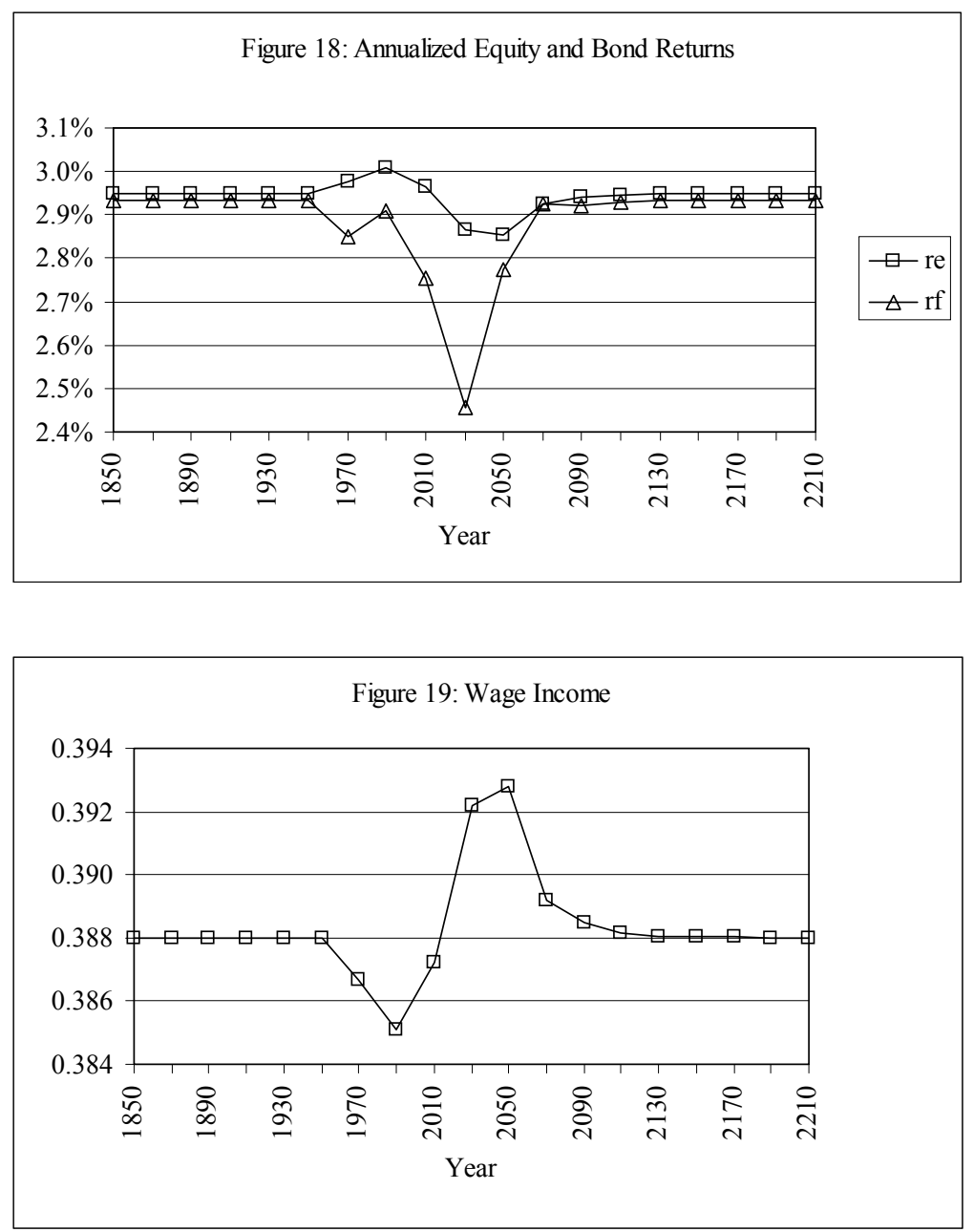

${ }^{25}$ A different version of the pay-as-you-go pension system, in which the retirement benefit is exogenous and the payroll tax rate endogenous, might do a better job at insuring agents against cohort-specific risk. 


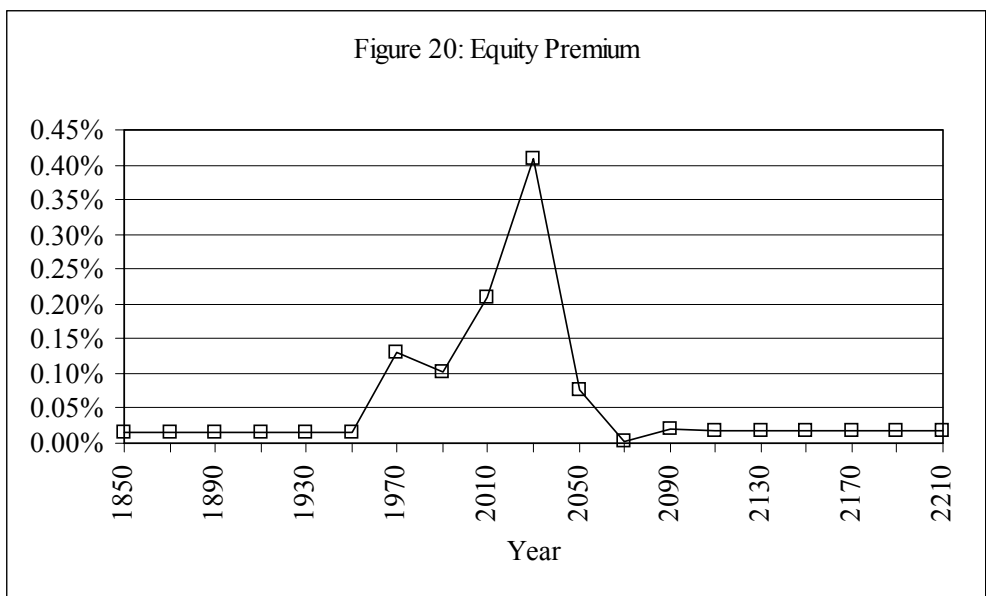

Simulating the boom-bust using (4') to model lifetime utility puts the earlier results in perspective. The key result, the decline in the riskfree rate relative to the return on capital as boom turns to bust, is stable across specifications. In 2010 the last cohort of the baby boom is forced to trade with the first cohort of the baby bust. As above, this disparity in size results in excess demand for the riskless asset, pushing down the riskfree rate to clear the bond market.

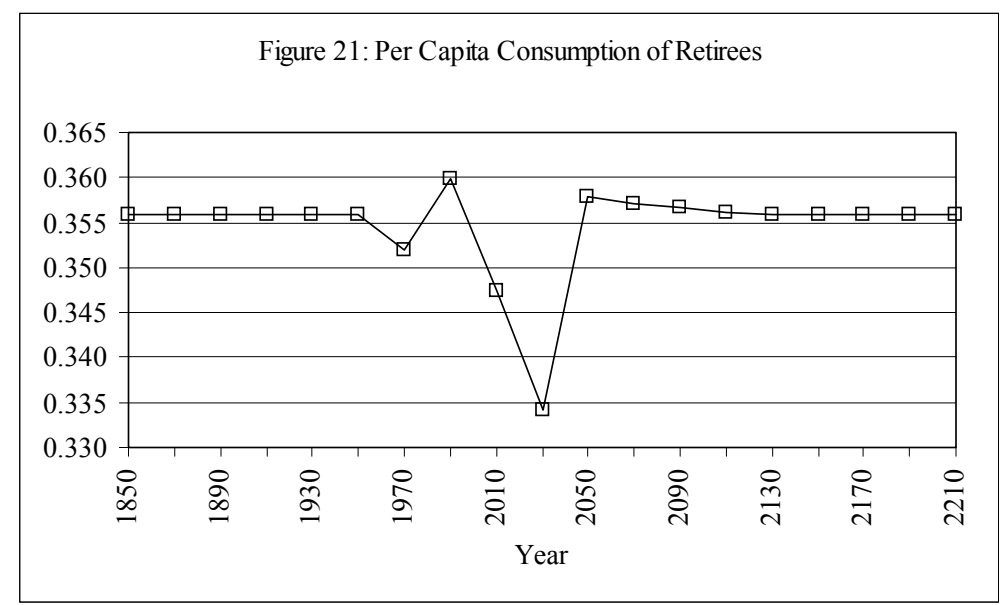

Figure 21 plots consumption of retirees, illustrating that the decline in the riskfree rate puts boomer cohorts at a distinct disadvantage as they go into retirement. Figure 22 plots discounted lifetime utility over the demographic shift, again from the perspective of young working-age. With young workers' utility defined over household consumption, boomer cohorts are now unambiguously worse of in utility terms than surrounding smaller cohorts. It is important to emphasize that investment behavior and model characteristics are stable whether young workers think in terms of per capita or household consumption. What changes is the importance of consumption in young working-age relative to consumption in later periods. With the reduced weight assigned to consumption in young working-age relative to later periods, asset market effects of demographic shifts become first-order. The reversal of the welfare result raises the interesting question of how to model parents' utility relative to that of their children. 26

${ }^{26}$ The reversal of the welfare result stems from the concavity of period utility, and would not obtain if period utility were linear in consumption, for example. As noted above, the model 


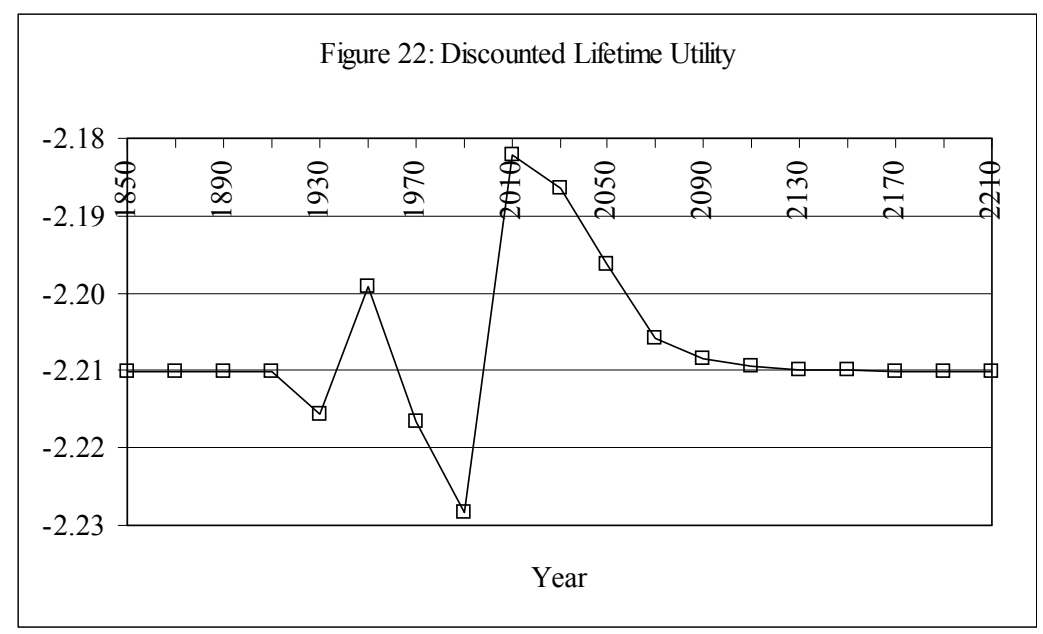

The magnitude of the asset market effects is comparable across specifications. In this specification the annualized expected return on capital amounts to 2.95 percent in equilibrium. This return peaks in 1990 at 3.01 percent, falling to a minimum of 2.85 percent in 2050. The annualized return on the riskfree asset is 2.93 percent in equilibrium, reaching a minimum of 2.46 percent in 2030. Again these effects are significant, particularly for older investors who want to minimize consumption risk in retirement. The total bond return in the 20 year period around 2030, the return to tail-end baby boomers, is 16 percent below equilibrium. As above these effects are also significant relative to other sources of uncertainty. The largest change in the return on capital, the decline going from 2010 to 2030 , amounts to 30 percent of the standard deviation of the period return (see Table 9).

\section{Conclusion}

This paper demonstrates that changes in the age distribution have significant effects on financial markets. This result is consistent with rational, forward-looking behavior and derives from the fact that in an overlapping generations model there is only a limited number of cohorts that trade at any point in time, in the absence of an infinitely-lived agent. A government that varies the stock of debt over time to insure agents against cohort-specific risk in asset markets would make up for this market incompleteness.

To summarize, in a setting where investors are rational and forward-looking, changes in the age distribution have an aggregate saving effect on factor returns and the riskfree rate. In addition, since agents shift from stocks to bonds as they age, the return differential increases when boom turns to bust. Since in the model only two cohorts trade at any point in time, agents cannot diversify this risk away, even though it has a sizeable impact on retirement consumption. It is worth noting that a pay-as-you-go pension scheme fails to insure agents against these cohort-specific asset market effects, since the same demographic effects that move returns against aging boomer cohorts also reduce the per capita retirement benefit. The model thus suggests that, to insure agents against these effects, government should vary the

abstracts from agents' decision to have children. As such the discussion on the welfare effects of the boom-bust should be seen as incomplete. 
supply of debt over time to smooth the riskfree rate. In essence this would amount to making transfers of wealth across generations, reflecting a political consensus that insurance against asset market effects of demographic shocks is worthwhile.

Within the context of the model the effects of demographic transitions on asset returns are non-trivial, both in absolute terms and relative to the effects of other fundamentals. And while the effects are small relative to the recent run-up in stock indices, the simulated baby boom-baby bust holds non-demographic fundamentals constant and ignores the possibility of a speculative bubble. 


\section{References}

Attanasio, O. and Violante, G. "The Demographic Transition in Closed and Open Economies: A Tale of Two Regions.” Mimeo, February 2000

Bakshi, G. and Chen, Z. "Baby Boom, Population Aging, and Capital Markets." Journal of Business, Vol. 67, No.2, 1994: 165 - 202

Bergantino, S. "Life Cycle Investment Behavior, Demographics, and Asset Prices."

Dissertation, M.I.T., September 1998

Brooks, R. "Population Aging and Global Capital Flows in a Parallel Universe." IMF Working Paper, WP/00/XX, May 2000

Brooks, R. “Asset Market and Savings Effects of Demographic Transitions.” Dissertation, Yale University, December 1998

Campbell, J., Cocco, J., Gomes, F. and Maenhout, P. "Investing Retirement Wealth: A LifeCycle Model." Mimeo, March 1999

Colvin, G. "How to Beat the Boomer Rush.” Fortune, August 18, 1997, 59 - 63

Constantinides, G., Donaldson, J. and Mehra, R. "Junior Can’t Borrow: A New Perspective on the Equity Premium Puzzle." Mimeo, May 1998

Den Haan, W. and Marcet, A. "Solving the Stochastic Growth Model by Parameterizing Expectations.” Journal of Business \& Economic Statistics 8(1990): 31 - 34

Den Haan, W. and Marcet, A. “Accuracy in Simulations.” Review of Economic Studies 61 (1994): $3-18$

Feldstein, M. and Ranguelova, E. "Individual Risk and Intergenerational Risk Sharing in an Investment Based Social Security System.” NBER Working Paper 6839, December 1998

French, K. and Poterba, J. "Investor Diversification and International Equity Markets." American Economic Review 81 (1991): 222 - 226

Heller, P. "Rethinking Public Pension Reform Initiatives.” IMF Working Paper, WP/98/61, April 1998

Hemming, R. "Should Public Pensions be Funded?" IMF Working Paper, WP/98/35, March 1998

Higgins, M. "Demography, National Savings and International Capital Flows." International Economic Review, Vol. 39 No. 2 (1998): 343-369 
Higgins, M. and Williamson, J. “Asian Demography and Foreign Capital Dependence.” NBER Working Paper 5560 (1996)

Ibbotson Associates. “Stocks, Bonds, Bills and Inflation: 1999 Yearbook.” 1999

Izvorski, I. “Asset Pricing with Heterogeneous Agents.” Mimeo, September 1997

Jagannathan, R. and Kocherlakota, N. "Why should Older People Invest Less in Stocks than Younger People?” Federal Reserve Bank of Minneapolis Quarterly Review, Summer 1996

Kocherlakota, N. “The Equity Premium: It's still a Puzzle.” Journal of Economic Literature, Vol. XXXIV (March 1996): 42 - 71

Mehra, R. and Prescott, E. “The Equity Premium: A Puzzle.” Journal of Monetary Economics 15(1985): 145 - 161

Passell, P. “The Year is 2010. Do you know where your Bull is?” The Sunday New York Times, March 10, 1996

Poterba, J. "Population Age Structure and Asset Returns: An Empirical Investigation." Mimeo, 1998

MaCurdy, T., and Shoven, J. "Stocks, Bonds and Pension Wealth." Topics in the Economics of Aging, NBER, 1992

Storesletten, K., Telmer, C. and Yaron, A. "Persistent Idiosyncratic Shocks and Incomplete Markets." Mimeo, June 1997 